\title{
Programmed death ligand-1 expression on donor T cells drives graft-versus-host disease lethality
}

\author{
Asim Saha, ${ }^{1}$ Roddy S. O'Connor, ${ }^{2}$ Govindarajan Thangavelu, ${ }^{1}$ Scott B. Lovitch, ${ }^{3}$ Durga Bhavani Dandamudi, ${ }^{4}$ Caleph B. Wilson, ${ }^{5}$ \\ Benjamin G. Vincent, ${ }^{6}$ Victor Tkachev, ${ }^{7}$ Jan M. Pawlicki, ${ }^{5}$ Scott N. Furlan, ${ }^{7}$ Leslie S. Kean, ${ }^{7}$ Kazutoshi Aoyama, ${ }^{1}$ Patricia A. Taylor, ${ }^{1}$ \\ Angela Panoskaltsis-Mortari, ${ }^{1}$ Rocio Foncea, ${ }^{8}$ Parvathi Ranganathan, ${ }^{9}$ Steven M. Devine, ${ }^{9}$ Joel S. Burrill, ${ }^{8}$ Lili Guo, ${ }^{10}$ \\ Catarina Sacristan, ${ }^{11}$ Nathaniel W. Snyder, ${ }^{10,12}$ Ian A. Blair, ${ }^{10}$ Michael C. Milone, ${ }^{2}$ Michael L. Dustin,${ }^{11,13}$ James L. Riley, ${ }^{5}$ \\ David A. Bernlohr, ${ }^{8}$ William J. Murphy, ${ }^{14}$ Brian T. Fife, ${ }^{15}$ David H. Munn, ${ }^{16}$ Jeffrey S. Miller, ${ }^{17}$ Jonathan S. Serody, ${ }^{6,18}$ \\ Gordon J. Freeman, ${ }^{19}$ Arlene H. Sharpe, ${ }^{3}$ Laurence A. Turka, ${ }^{20}$ and Bruce R. Blazar ${ }^{1}$
}

'Masonic Cancer Center and Department of Pediatrics, Division of Blood and Marrow Transplantation, University of Minnesota, Minneapolis, Minnesota, USA. ${ }^{2}$ Department of Pathology and Laboratory Medicine, Perelman School of Medicine, University of Pennsylvania, Philadelphia, Pennsylvania, USA. ${ }^{3}$ Department of Microbiology and Immunobiology, Harvard Medical School and Department of Pathology, Brigham and Women's Hospital, Boston, Massachusetts, USA. ${ }^{4}$ Sackler Graduate Program, New York University School of Medicine, New York, New York, USA. ${ }^{5}$ Department of Microbiology, Perelman School of Medicine, University of Pennsylvania, Philadelphia, Pennsylvania, USA. ${ }^{6}$ Department of Medicine, University of North Carolina, Chapel Hill, North Carolina, USA. 'Department of Pediatrics, University of Washington, Seattle, Washington, USA. ${ }^{8}$ Department of Biochemistry, Molecular Biology and Biophysics, University of Minnesota, Minneapolis, Minnesota, USA. ${ }^{9}$ Department of Medicine, The Ohio State University Comprehensive Cancer Center, Columbus, Ohio, USA. ${ }^{10}$ Penn SRP Center, Department of Systems Pharmacology and Translational Therapeutics, Perelman School of Medicine, University of Pennsylvania, Philadelphia, Pennsylvania, USA. "Department of Pathology, New York University School of Medicine, New York, New York, USA. ${ }^{12}$ A.J. Drexel Autism Institute, Drexel University, Philadelphia, Pennsylvania, USA. ${ }^{13}$ Nuffield Department of Orthopedics, Rheumatology and Musculoskeletal Sciences, The University of Oxford, Oxford, United Kingdom. ${ }^{14}$ Department of Dermatology and Internal Medicine, UCD, Sacramento, California, USA. ${ }^{15}$ Department of Medicine and Center for Immunology, University of Minnesota, Minneapolis, Minnesota, USA. ${ }^{16}$ Department of Pediatrics, Georgia Regents University, Augusta, Ceorgia, USA. ${ }^{17}$ Department of Medicine, Division of Hematology, Oncology and Transplantation, University of Minnesota, Minneapolis, Minnesota, USA. ${ }^{18}$ Department of Microbiology and Immunology, University of North Carolina, Chapel Hill, North Carolina, USA. ${ }^{19}$ Department of Medical Oncology, Dana-Farber Cancer Institute, and ${ }^{20}$ Center for Transplantation Sciences, Department of Surgery, Massachusetts General Hospital and Harvard Medical School, Boston, Massachusetts, USA

Programmed death ligand-1 (PD-L1) interaction with PD-1 induces T cell exhaustion and is a therapeutic target to enhance immune responses against cancer and chronic infections. In murine bone marrow transplant models, PD-L1 expression on host target tissues reduces the incidence of graft-versus-host disease (GVHD). PD-L1 is also expressed on T cells; however, it is unclear whether PD-L1 on this population influences immune function. Here, we examined the effects of PD-L1 modulation of T cell function in CVHD. In patients with severe CVHD, PD-L1 expression was increased on donor T cells. Compared with mice that received WT T cells, GVHD was reduced in animals that received T cells from PdI1 ${ }^{-1-}$ donors. PD-L1-deficient T cells had reduced expression of gut homing receptors, diminished production of inflammatory cytokines, and enhanced rates of apoptosis. Moreover, multiple bioenergetic pathways, including aerobic glycolysis, oxidative phosphorylation, and fatty acid metabolism, were also reduced in T cells lacking PD-L1. Finally, the reduction of acute CVHD lethality in mice that received $P d I 1^{-/-}$donor cells did not affect graft-versus-leukemia responses. These data demonstrate that PD-L1 selectively enhances T cell-mediated immune responses, suggesting a context-dependent function of the PD-1/ PD-L1 axis, and suggest selective inhibition of PD-L1 on donor T cells as a potential strategy to prevent or ameliorate GVHD.

\section{Introduction}

Acute graft-versus-host disease (GVHD), induced by donor T cells that recognize host alloantigenic disparities, is a significant cause of morbidity and mortality following allogeneic bone marrow transplantation $(\mathrm{BMT})(1,2)$. Current approaches to prevent or treat GVHD focus on blocking $\mathrm{T}$ cell activation or the proinflam-

Authorship note: A.H. Sharpe, L.A. Turka, and B.R. Blazar contributed equally to this work. Note regarding evaluation of this manuscript: Manuscripts authored by scientists associated with Duke University, The University of North Carolina at Chapel Hill, Duke-NUS, and the Sanford-Burnham Medical Research Institute are handled not by members of the editorial board but rather by the science editors, who consult with selected external editors and reviewers.

Conflict of interest: The authors have declared that no conflict of interest exists. Submitted: December 1, 2015; Accepted: April 28, 2016. Reference information: / Clin Invest. 2016;126(7):2642-2660. doi:10.1172/JCI85796. matory products of activated $\mathrm{T}$ cells using immunosuppressive drugs such as calcineurin inhibitors, mycophenolate mofetil, and corticosteroids. Many new drugs in various stages of development aim to more specifically target selective $\mathrm{T}$ cell functions or activated T cells (3), including agents designed to block T cell costimulatory pathways such as CD28, CD154, and ICOS.

Programmed death-1 (PD-1) is an inhibitory receptor that attenuates $T$ cell activation by recruitment of phosphatases, which negatively regulate $\mathrm{T}$ cell receptor (TCR) signaling $(4,5)$. While PD-1 expression is low in resting T cells, it is inducible following $\mathrm{T}$ cell activation, and is also found on activated B cells, NKT cells, and activated monocytes (6). The importance of this molecule in restraining immune responses has been made readily apparent by numerous studies that show that blockade of PD-1 provides effective immune stimulation against tumors (7-10). 
A

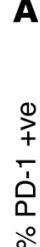

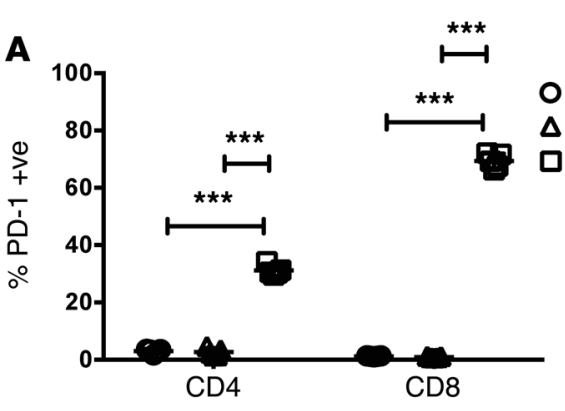

c
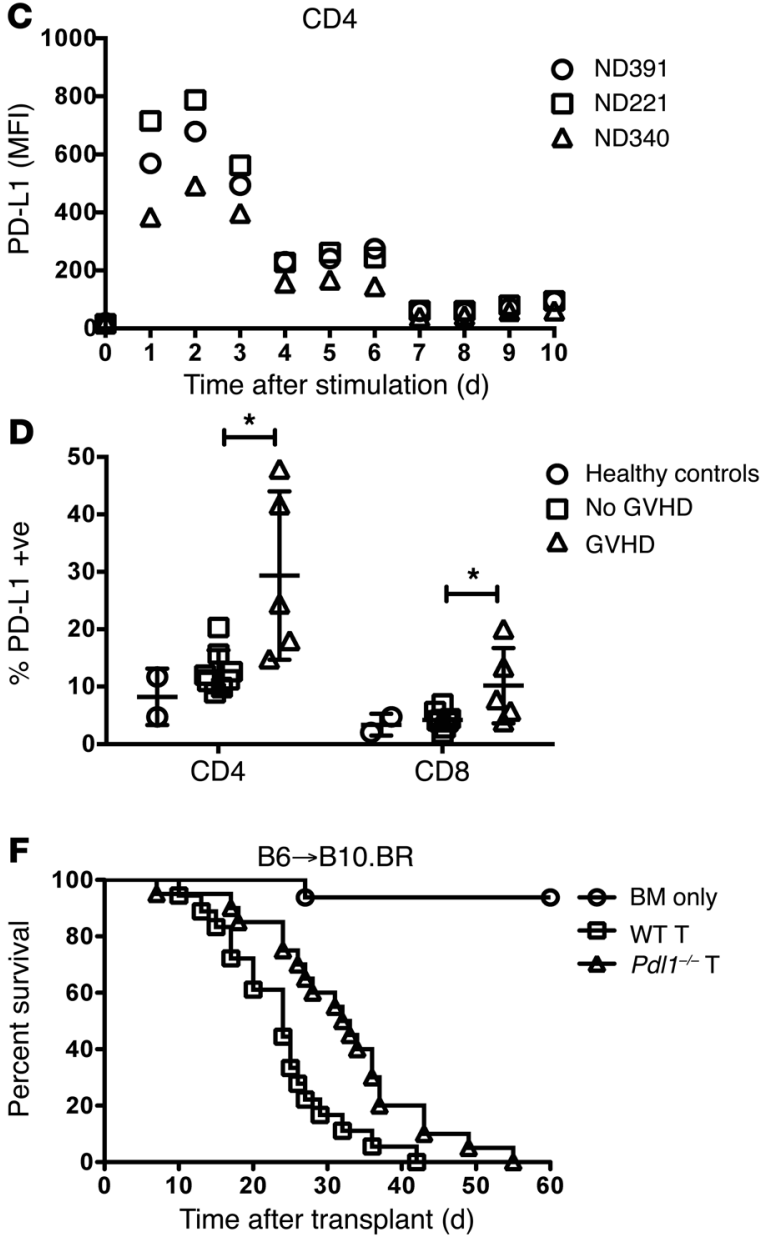
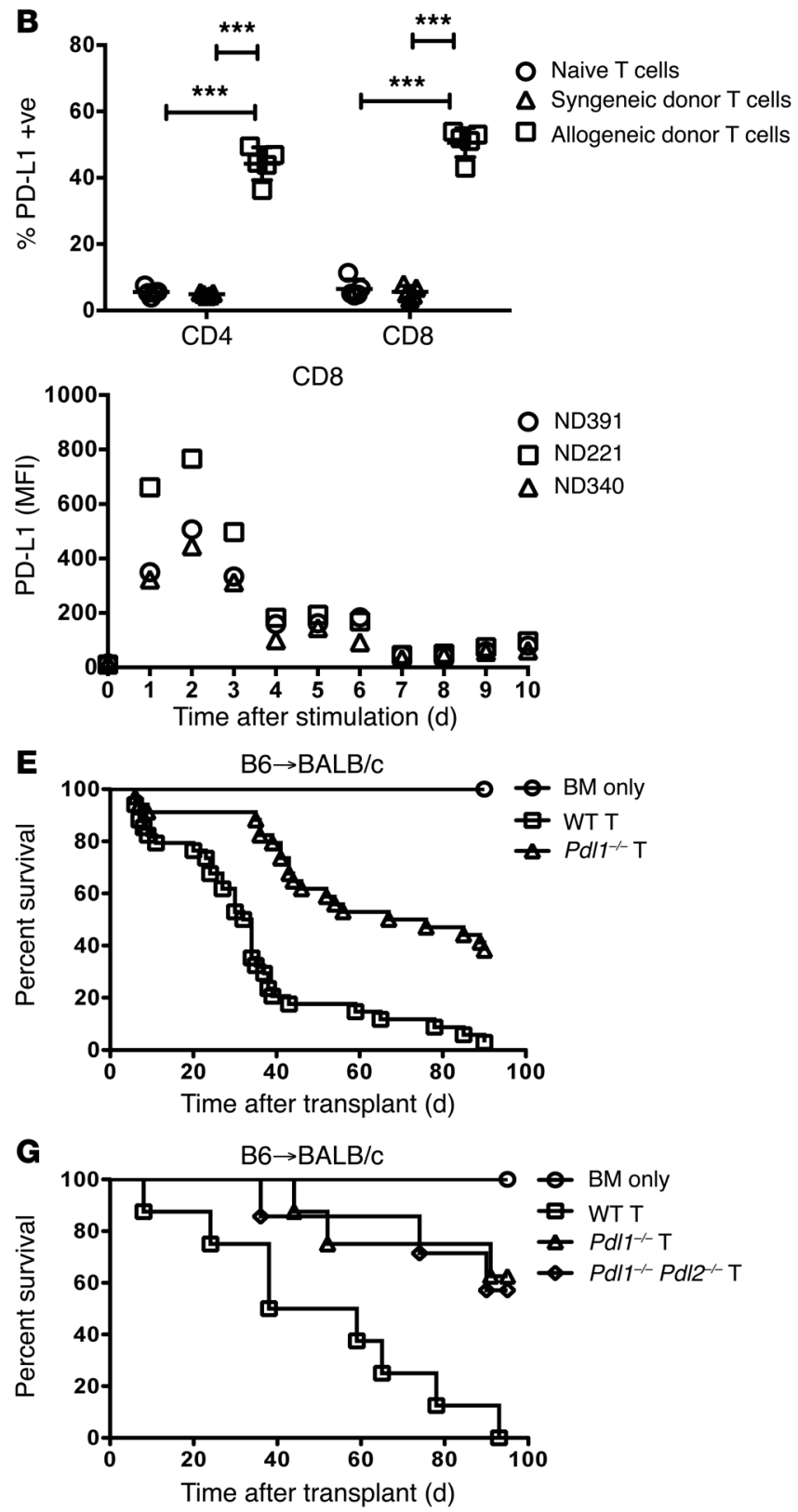

Figure 1. GVHD-induced PD-L1 upregulation on donor Teffs contributes to lethality. (A and B) Lethally irradiated B6 or BALB/C recipients were infused with $10^{7}$ WT B6 BM cells plus $6 \times 10^{6}$ B6 Ly5.2 (CD45.1+) splenocytes. Mice were sacrificed on day 5 after BMT ( $n=5$ per group), and splenic donor CD4 and CD8 T cells were analyzed by flow cytometry for PD-1 (A) or PD-L1 (B) expression. Splenocytes of naive B6 Ly5.2 mice $(n=5)$ were included in the analysis. (C) T cells isolated from normal human donors $(n=3)$ were stimulated with anti-CD3/CD28 beads, and CD4 and CD8 T cells were stained for PD-L1 expression every 24 hours after stimulation. (A-C) Data are representative of 2 independent experiments. (D) Human PBMCs were collected from healthy volunteers and from patients after allogeneic BMT with or without GVHD at the time of collection (Supplemental Table 1). CD4 and CD8 T cells were then stained and analyzed for PD-L1 expression using the gating strategy as shown in Supplemental Figure 2A. (E) Lethally irradiated BALB/c recipients were infused with $10^{7}$ WT B6 BM cells alone or with $1 \times 10^{6}$ WT B6 or Pdl1 $1^{-/-}$purified T cells. Kaplan-Meier survival plot represents pooled data from 4 independent experiments $(n=31-34$ per group; recipients of WT vs. Pdl1 $1^{-/-}$donor T cells, $\left.P<0.0001\right)$. (F) Lethally irradiated B10.BR recipients were infused with $10^{7}$ WT B6 BM cells alone or with $3 \times$ $10^{6}$ WT B6 or PdI1/-/ purified T cells. Kaplan-Meier survival plot represents pooled data from 2 independent experiments $(n=16-20$ per group; recipients of WT vs. $P d 11^{1 /-}$ donor T cells, $\left.P=0.0047\right)$. (C) Lethally irradiated BALB/c recipients were infused with $10^{7}$ WT B6 BM cells alone or with $1 \times 10^{6} \mathrm{WT} B 6, P d 11^{-/-}$, or $P d 11^{-/-} P d 12^{-/-}$purified T cells. Kaplan-Meier survival plot of transplanted mice is shown ( $n=8$ per group; recipients of WT vs. $P d 17^{-/-}$donor T cells, $P=0.006$; recipients of WT vs. Pdl1 ${ }^{-/-} P d l 2^{-1-}$ donor T cells, $\left.P=0.011\right)$. Data represent mean \pm SEM $(\mathbf{A}, \mathbf{B}$, and $\mathbf{D})$, and $P$ values were calculated by 2 -tailed $t$ test $(\mathbf{A}, \mathbf{B}$, and D) or log-rank test (E-G). ${ }^{*} P<0.05,{ }^{* *} P<0.001$.

PD-1 has 2 identified ligands, PD-L1 and PD-L2, which differ in their expression patterns, as PD-L1 is expressed on both hematopoietic and nonhematopoietic cells (11-14), whereas PD-L2 expression is restricted primarily to DCs and macro- phages $(14,15)$. PD-L1 is constitutively expressed at low levels and induced by IFNs, whereas PD-L2 is induced primarily by GM-CSF and IL-4 (14). This broad expression of PD-L1 suggests that PD-L1 may regulate self-reactive $\mathrm{T}$ or $\mathrm{B}$ cells and inflammatory responses 
A

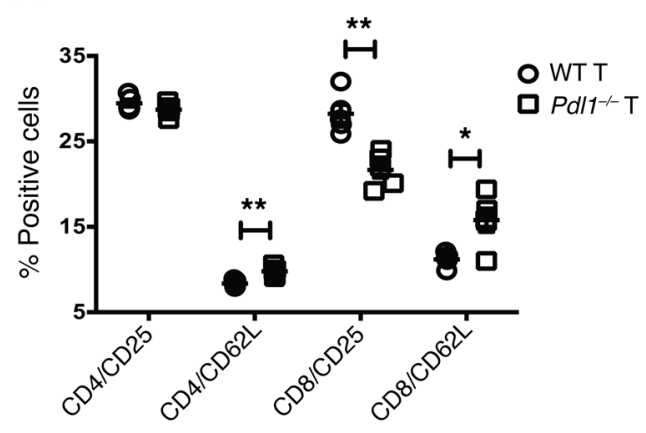

c
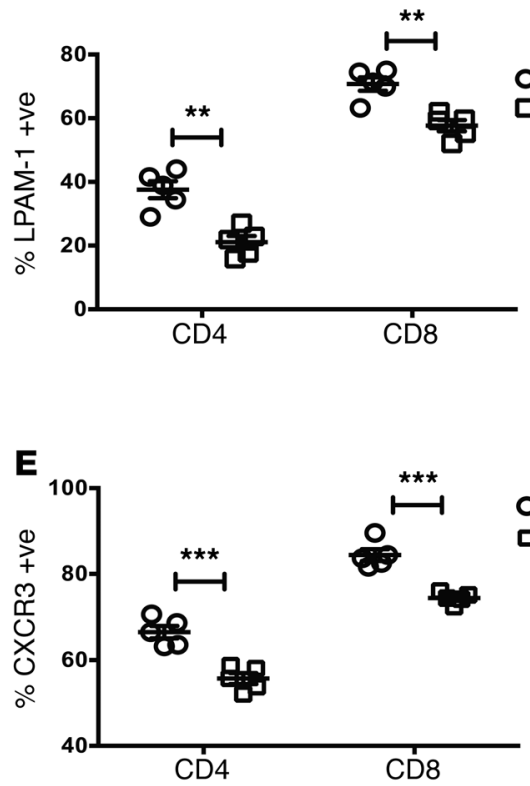

G
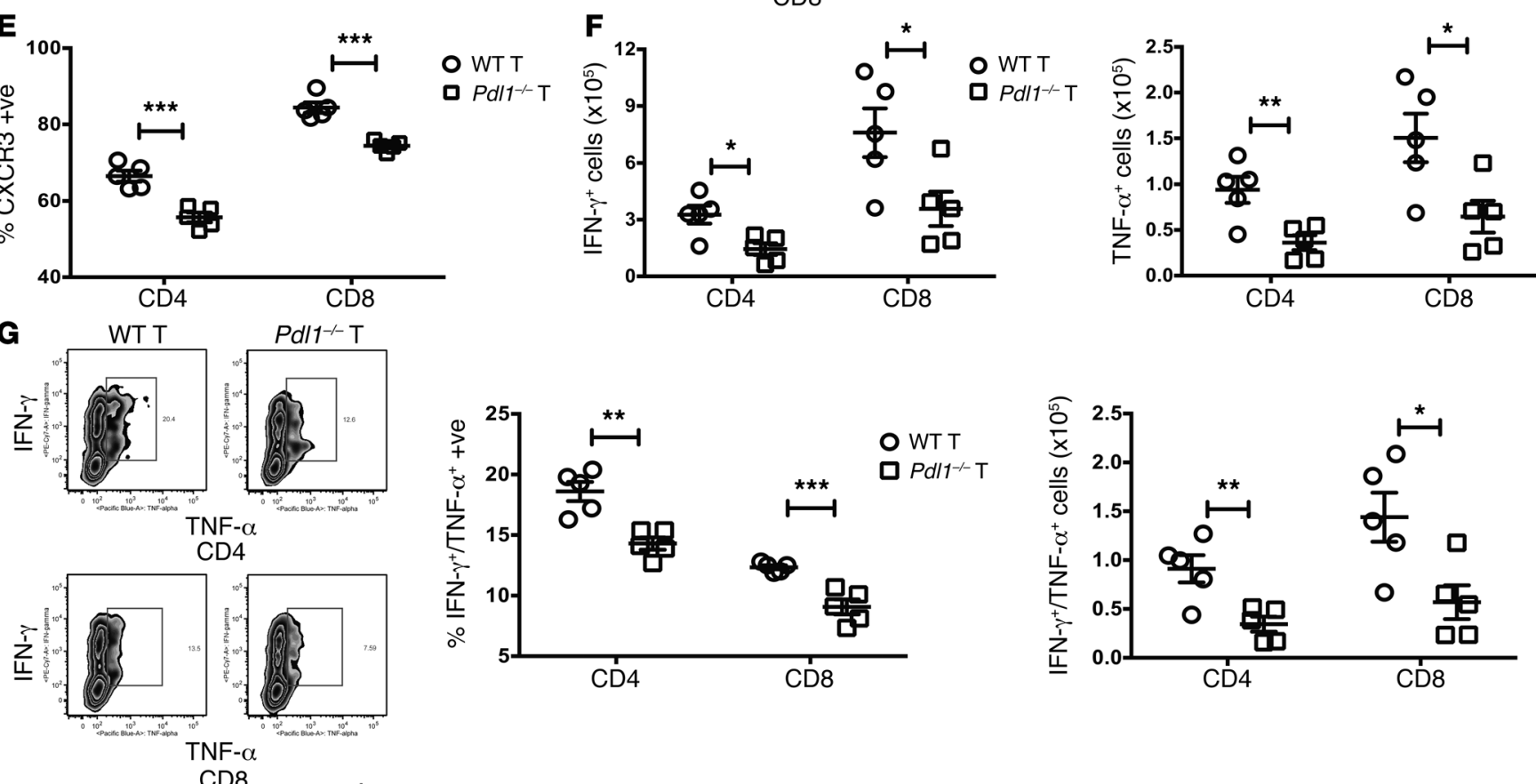

D
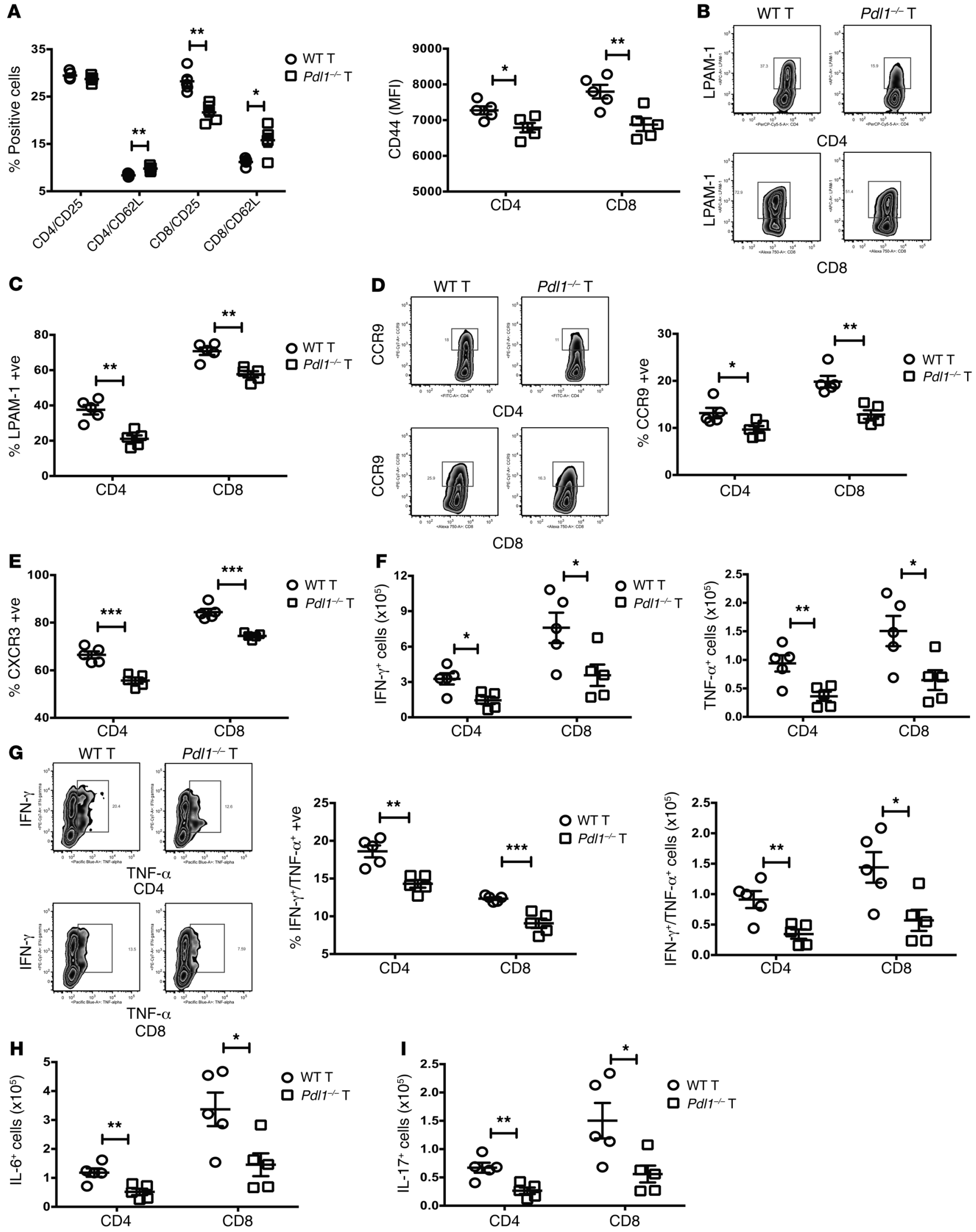
Figure 2. PdI1/-- versus WT donor T cells have reduced expression of gut homing and chemokine receptors, and inflammatory cytokines in spleen. Lethally irradiated BALB/c recipients were infused with $10^{7}$ WT B6 BM cells plus $2 \times 10^{6}$ WT B6 or PdI1 ${ }^{-/}$purified T cells. Mice were sacrificed ( $n=5$ per group) on day 7 after BMT, and donor CD4 and CD8 T cells in spleen were analyzed by flow cytometry for the expression of CD25, CD62L, and CD44 (A), LPAM-1 (B and C), CCR9 (D), and CXCR3 (E). MFI, mean fluorescence intensity. (F-I) Intracellular cytokine staining was performed on day 7 after BMT to detect the number of donor T cells producing IFN- $\gamma$, TNF- $\alpha$, IFN- $\gamma$ / TNF- $\alpha$, IL-6, or IL-17. (A-I) Data are representative of 2-3 independent experiments. Data represent mean $\pm \mathrm{SEM}$, and $P$ values were calculated by 2-tailed $t$ test $(\mathbf{A}$ and $\mathbf{C}-\mathbf{I}) .{ }^{*} P<0.05,{ }^{* *} P<0.01,{ }^{* * *} P<0.001$.

in nonlymphoid as well as lymphoid organs. Further complexity is added to the system by the fact that PD-L1 has a second ligand, namely B7-1 (CD80) (16).

The specific inhibitory role of PD-L1 in multiple types of immune responses is well established (17-22). In the specific case of BMT, PD-L1 expressed by recipient hematopoietic and parenchymal cells induces alloreactive CD8 T cell dysfunction and restrains graft-versus-leukemia effects $(23,24)$. These studies have all focused on the role of PD-L1 on non-T cells in restraining T cell responses. However, while, as noted above, PD-L1 is expressed as well on T cells themselves, its function on T cells during physiologic in vivo immune responses is not known. To address this issue, we investigated the role of PD-L1 expressed by donor T cells in a model of acute GVHD and isolated from patients with acute GVHD. Contrary to our expectation that PD-L1 would act to suppress the in vivo $\mathrm{T}$ cell response, we observed a novel $\mathrm{T}$ cell-intrinsic function for PD-L1 in promoting murine GVHD via optimizing the metabolic activity and survival of alloreactive $T$ cells. These findings suggest that selective PD-L1 reduction in donor T cells may provide a new therapeutic strategy for inhibiting GVHD lethality, an approach that may be applicable to other diseases as well.

\section{Results}

Decreased GVHD mortality caused by PD-L1-deficient donor T cells. PD-1 and PD-L1 are known T cell activation antigens, but their expression had not been analyzed in the context of GVHD. To do so, lethally irradiated C57BL/6 (B6) or BALB/c recipients were infused with WT B6 bone marrow (BM) and B6 Ly5.2 spleen cells to induce GVHD. On day 5 after BMT, PD-1 and PD-L1 expression on allogenic donor $\mathrm{T}$ cells was significantly increased compared with that on syngeneic donor $\mathrm{T}$ cells and $\mathrm{T}$ cells from naive controls (Figure 1, A and B). PD-1 and PD-L1 induction was severely impaired in Ifngr ${ }^{-/-}$donor $\mathrm{T}$ cells, indicating that elevated IFN- $\gamma$ during GVHD contributes to their upregulation (Supplemental Figure 1, A and B; supplemental material available online with this article; doi:10.1172/JCI85796DS1). In contrast to these observations with PD-1 and PD-L1, less than $4 \%$ of donor T cells expressed PD-L2 during the GVHD response (Supplemental Figure 1C).

While PD-L1 is constitutively expressed at low levels on mouse $\mathrm{T}$ cells, its expression is inducible on human $\mathrm{T}$ cells. To investigate PD-L1 expression on human T cells, $\mathrm{T}$ cells isolated from PBMCs of normal healthy donors were stimulated with Human $\mathrm{T}$-Expander anti-CD3/CD28 beads for 3 days, and $\mathrm{T}$ cells then were analyzed daily for PD-L1 expression. Following stimulation, there was a marked increase in PD-L1 expression on both CD4 and CD8 T cells with peak expression on day 2 and then gradual diminishing (Figure 1C). To determine whether GVHD patients had increased PD-L1 expression, human PBMCs were collected from healthy volunteers and from patients after allogeneic BMT without GVHD or at the time of GVHD diagnosis (Supplemental Table 1). We observed a significant increase in PD-L1 expression on both CD4 and CD8 T cells in GVHD patients, whereas no significant difference was detected in patients with no GVHD versus healthy controls (Figure 1D and Supplemental Figure 2).

Given its coinhibitory activity when PD-L1 is expressed on host parenchymal cells during GVHD (22), we postulated that PD-L1 expression on activated donor T cells would inhibit GVHD by downregulating donor antihost $\mathrm{T}$ cell responses through $\mathrm{T}$ cell-T cell interactions. Surprisingly, however, $\mathrm{T}$ cell-mediated GVHD lethality and clinical scores were markedly ameliorated in recipients of $\mathrm{Pdl1}^{-/}$donor T cells (Figure 1E and Supplemental Figure $3, \mathrm{~A}$ and $\mathrm{B})$. These findings were replicated in a second model $(\mathrm{B} 6 \rightarrow \mathrm{B} 10 . \mathrm{BR})$, where again GVHD was much milder when donor $\mathrm{T}$ cells were PD-L1 deficient (Figure 1F and Supplemental Figure 3C). Finally, concomitant PD-L2 deficiency did not alter lethality in BALB/c recipients of $P d l 1^{-/}$versus $P d l 1^{-/} \mathrm{Pdl2}^{-/}$donor T cells at doses of $1 \times 10^{6}$ (Figure 1G) or $2 \times 10^{6}$ (PO.417, data not shown) cells, indicating that, in contrast to its inhibitory effect on host parenchymal cells, PD-L1 but not PD-L2 functions in donor T cells to augment GVHD lethality.

Decreased gut homing and cytokine production by $\mathrm{Pdl1}^{-/}$donor $T$ cells. As the gut is a primary GVHD target organ, we analyzed the expression of gut adhesion and chemokine homing receptors (25, 26) as well as cell activation markers. We found that $P d l 1^{-/}$donor $\mathrm{T}$ cells had decreased expression of selected activation markers (CD25, CD44, and lysosomal marker CD107a) and higher levels of CD62L expression (Figure 2A and data not shown). Pdl1 ${ }^{-/-}$ donor $\mathrm{T}$ cells had decreased expression in gut homing receptors as denoted by LPAM- $1\left(\alpha_{4} \beta_{7}\right)$, CCR9, and CXCR3 compared with WT donor T cells (Figure 2, B-E), and the percentage and absolute numbers of $P d l 1^{-/}$donor T cells expressing IFN- $\gamma$, TNF- $\alpha$, IFN- $\gamma /$ TNF- $\alpha$, IL- 6 , or IL-17 were significantly reduced on day 7 after BMT (Figure 2, F-I, and data not shown). Consistent with the reduced activation and cytokine expression data, histologic analysis on day 24 showed a reduction in the damage to the colon and ileum in recipients of $\mathrm{Pdll}^{-/}$donor T cells (Figure 3A). This was associated with a reduction in absolute numbers and proliferation of donor T cells (Figure 3B), and expression of proinflammatory cytokines (Figure 3, C-F) by lamina propria lymphocytes isolated from colon (Figure 3, B-F) and small intestine (data not shown). Finally, we measured epithelial integrity of the gastrointestinal tract by oral administration of FITC-dextran, which enters into the bloodstream if the epithelial barrier has been compromised (27). As expected given a reduction in histologic scores, we found better-preserved epithelial integrity as well in recipients of $\mathrm{Pdl1}^{-1-}$ compared with WT donor T cells (Figure 3G).

Decreased Teff function is central to reduced GVHD with Pdl1 ${ }^{-1-}$ donor $T$ cells. Tregs are able to modulate GVHD severity and lethality $(28,29)$, leading us to ask whether PD-L1 deficiency on donor $\mathrm{T}$ cells was acting to lessen disease via effects on Tregs. We found that WT Tregs activated in vitro had elevated expression of PD-1 and PD-L1 but not PD-L2 as compared with resting T cells 

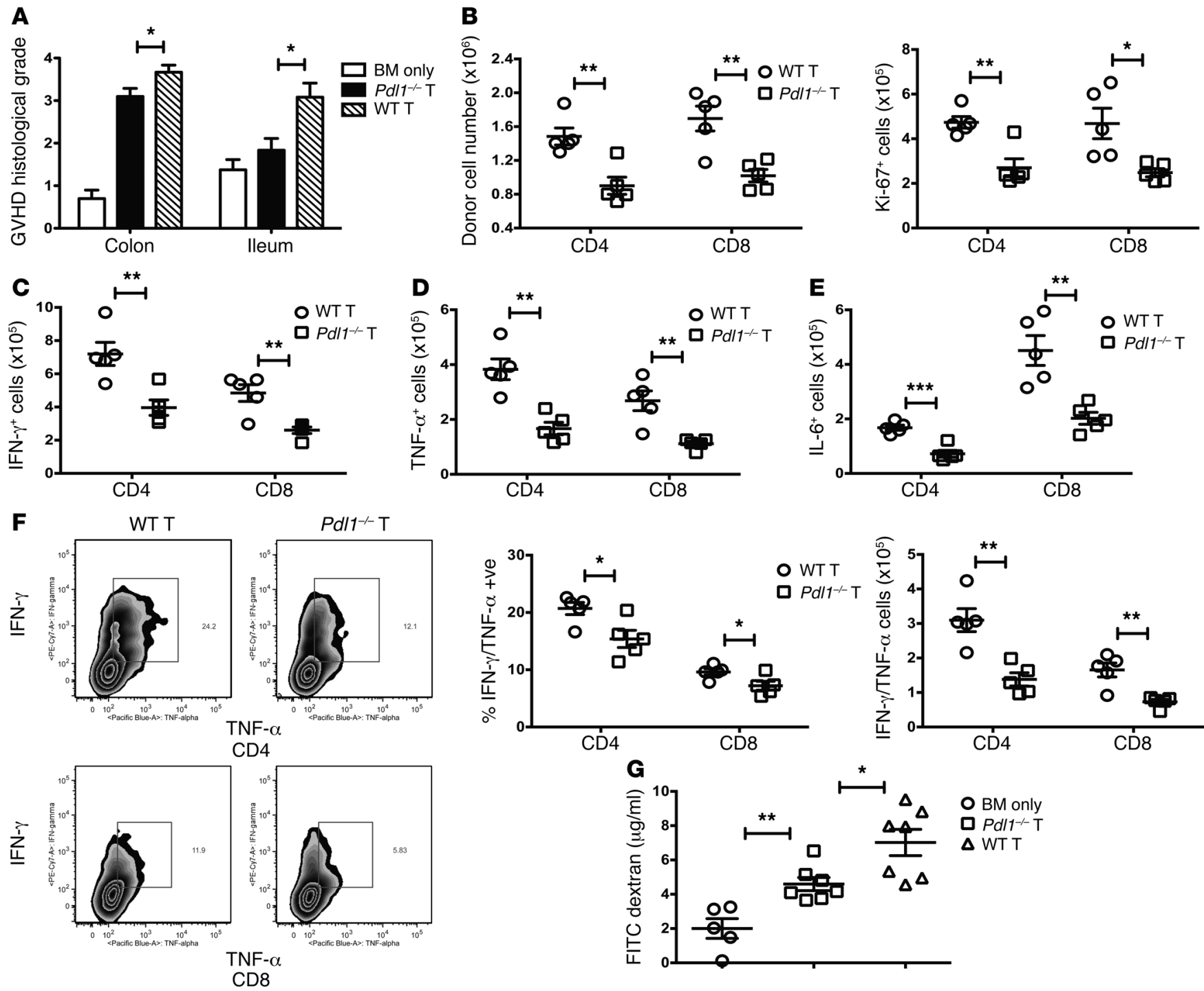

Figure 3. PdI1/-- versus WT donor T cells promote less gut injury in recipients. Lethally irradiated BALB/c recipients were infused with $10^{7}$ WT B6 BM cells alone or with $2 \times 10^{6}$ WT B6 or Pdl1 $7^{-/-}$purified T cells. (A) Mice were sacrificed on day 24 after BMT ( $n=5-7$ per group), and H\&E-stained tissue sections were scored for GVHD. (B-F) Lethally irradiated BALB/c mice were infused with $10^{7}$ WT B6 BM cells plus $2 \times 10^{6}$ WT B6 or Pdl1 ${ }^{-/}$purified T cells. Mice were sacrificed on day 24 after BMT ( $n=10$ per group), and lymphocytes isolated from colon ( 2 colons were pooled to make 1 pooled sample and 5 pooled samples per group) were analyzed by flow cytometry. (B) Donor T cells were analyzed for total cell numbers or intracellular expression of Ki-67. (C-F) Intracellular cytokine staining was performed to detect the number of donor T cells producing IFN- $\gamma$, TNF- $\alpha$, IL-6, or IFN- $\gamma /$ TNF- $\alpha$. (C) FITC-dextran was administered orally on day 24 after BMT ( $n=5-7$ per group), and plasma levels were measured after 4 hours. (A-G) Data are representative of 2 independent experiments. Data represent mean $\pm \mathrm{SEM}$, and $P$ values were calculated by 2 -tailed $t$ test $(\mathbf{A}-\mathbf{G}) .{ }^{*} P<0.05,{ }^{* *} P<0.01,{ }^{* * *} P<0.001$.

(Figure 4A and data not shown). However, despite the ability of activation to induce both PD-1 and PD-L1 on Tregs, we found no functional defect in $\mathrm{Pdll}^{-/-}$Tregs. In vitro, $\mathrm{Pdl1}^{-/-}$Tregs suppressed effector T cell (Teff) proliferation more effectively than WT Tregs (Figure 4B). Moreover, in vivo, in a system where supplementary Tregs are used to mitigate GVHD, $\mathrm{Pdl1}^{-1-}$ Tregs were as effective as WT Tregs in improving survival of the animals (Figure 4C), whereas $P d l 1^{-1-}$ Teffs in the absence of Tregs were unable to cause the same severity of GVHD lethality as WT Teffs in the absence of Tregs (Figure 4D).

We next investigated whether $\mathrm{Pdl1}^{-/-}$donor T cells would influence the expansion of induced Tregs (iTregs) following alloBMT. Lethally irradiated BALB/c recipients were infused with
B6 CD45.1 $1^{+}$BM cells plus CD25-depleted CD45.2+ WT B6 or $\mathrm{Pdl1}^{--}$purified T cells. Donor T cell-derived CD $4^{+} \mathrm{Foxp}^{+}{ }^{+}$Tregs in spleen showed a very modest increase in frequency and intensity in recipients of $\mathrm{Pdl1}^{-/}$versus WT T cells with mean frequency less than $2.5 \%$ on day 7 after BMT in both groups (Supplemental Figure 4A). The mean frequencies of donor $\mathrm{T}$ cell-derived $\mathrm{CD}^{+}{ }^{+}$Foxp $^{+}{ }^{+}$Helios $^{+}, \mathrm{CD}_{4}{ }^{+} \mathrm{Foxp}^{+} \mathrm{CD}^{+} \mathrm{O} 4^{+}$, and $\mathrm{CD} 4^{+} \mathrm{Foxp}^{+}$ PD- $1^{+}$Tregs were $<1.2 \%, 1.4 \%$, and $1.7 \%$, respectively, with no differences in recipients of WT versus Pdl1 ${ }^{-\digamma}$ donor T cells (data not shown), whereas mean frequencies of WT donor BM-derived $\mathrm{CD} 4^{+} \mathrm{Foxp}^{+}{ }^{+}$and $\mathrm{CD} 4^{+}{ }^{+} \mathrm{Foxp} 3^{+} \mathrm{Helios}^{+}$Tregs were increased up to $9.0 \%$ on day 14 after BMT with no differences in recipients of WT versus $P d l 1^{-/}$donor T cells (Supplemental Figure $4 \mathrm{~B}$ and data 
A
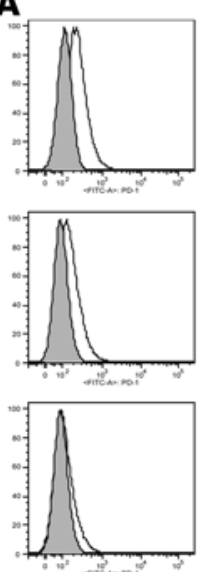

PD-1
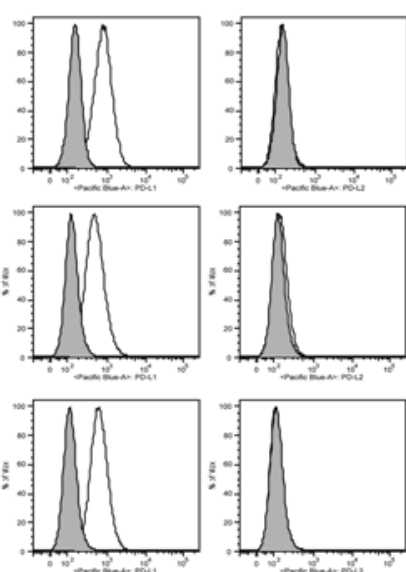

PD-L1
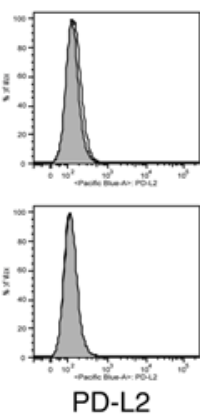

Day 4

Day 11
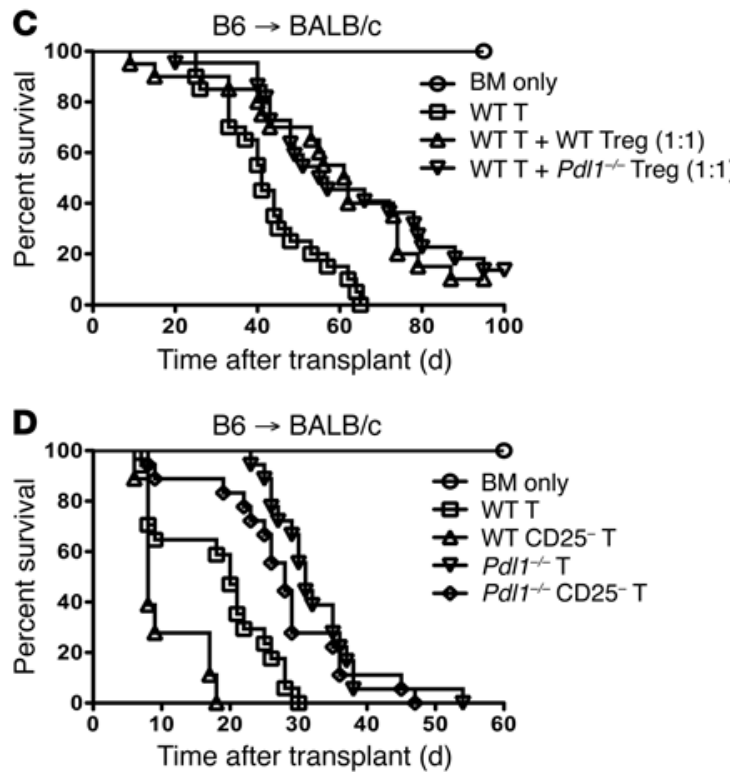

B
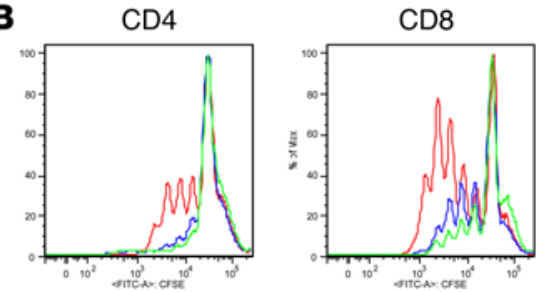

- Responder cells

Responder cells + WT Tregs

Responder cells + Pdl1 ${ }^{--}$Tregs

Day 7

Responder:Treg (1:1)
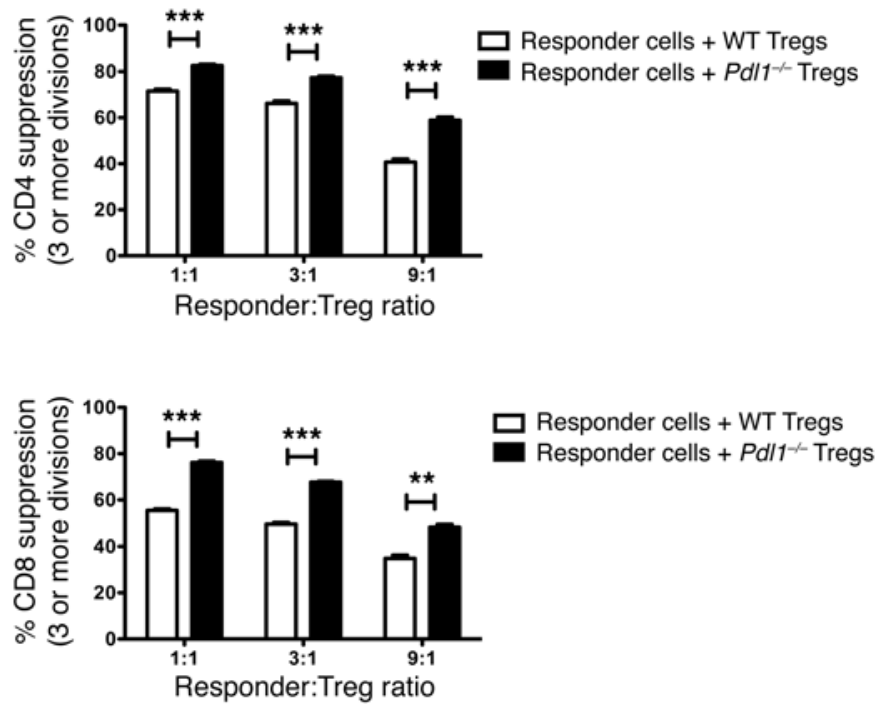

Figure 4. Reduced GVHD lethality in recipients of PdI1/-- versus WT donor T cells is independent of donor Treg function. (A) Tregs were isolated from naive WT BALB/C mice and were cultured with recombinant human IL-2 and CD3/CD28 beads. CD4 ${ }^{+}$CD25+Foxp3 $3^{+}$cells were analyzed by flow cytometry for PD-1, PD-L1, and PD-L2 expression on day 4, day 7, and day 11. Shaded histogram: isotype-matched control Ab. (B) Tregs were isolated from naive WT B6 or Pd17\%- mice. Naive B6 Ly5.2 mouse splenocytes were labeled with CFSE and used as responder cells. Responder cells were stimulated with anti-mCD3 $A b$ and were cultured with or without freshly isolated Tregs. T cell proliferation was determined by CFSE dilution on day 4 using flow cytometry. (A and B) Data are representative of 2 independent experiments. (C) Lethally irradiated BALB/c recipients were infused with $10^{7}$ WT B6 BM cells alone, or with $1 \times 10^{6}$ WT B6 purified T cells, or with $1 \times 10^{6}$ WT B6 purified T cells plus $1 \times 10^{6}$ WT B6 purified Tregs or $1 \times 10^{6}$ PdI1 $1^{-/}$purified Tregs. Kaplan-Meier survival plot represents pooled data from 2 independent experiments $(n=16-22$ per group; WT T cells vs. WT T cells + WT Tregs, $P=0.0014 ;$ WT T cells vs. WT T cells + $P d 11^{-/-}$Tregs, $\left.P=0.0004\right)$. (D) Lethally irradiated BALB/c recipients were infused with $10^{7}$ WT B6 BM cells alone, or with $2 \times 10^{6}$ WT B6 or Pdl1 $/-$ purified T cells, or with $2 \times 10^{6}$ WT B6 or PdI1 ${ }^{-/-}$CD25-depleted purified T cells. Kaplan-Meier survival plot represents pooled data from 2 independent experiments ( $n=16$-18 per group; WT T cells vs. WT CD25-depleted T cells, $P=0.0003 ; P d 11^{-/-}$T cells vs. Pdl1 ${ }^{--}$CD25-depleted T cells, $P=0.2306$; WT vs. $P d 11^{-/-}$T cells, $P<0.0001)$. (B) Data represent mean \pm SEM. $P$ values were calculated by 2 -tailed $t$ test $(\mathbf{B})$ or log-rank test $(\mathbf{C}$ and $\mathbf{D})$. ${ }^{* *} P<0.01,{ }^{* * *} P<0.001$.

not shown). These data are consistent with our previous findings that iTregs fail to be generated in high number in vivo because of IL-21 production during acute GVHD (30).

Together these data argue that despite expression of PD-L1 on activated $\mathrm{T}$ cells, it was cell-intrinsic differences in Teffs that were responsible for reduced lethality in recipients of $\mathrm{Pdll}^{-/}$- donor $\mathrm{T}$ cells.

Higher expression of inhibitory receptors by Pdl1 ${ }^{-/}$donor T cells leads to reduced Tefffunction. Given the data above suggesting that reduced Teff function is responsible for the reduction in GVHD caused by $\mathrm{Pdll}^{-/}$- donor T cells, we next investigated inhibitory receptor expres- sion early after BMT. A cotransfer strategy was used in which equal numbers of congenically marked WT and $P d l 1^{-1-} \mathrm{T}$ cells were infused along with BM into lethally irradiated BALB/c recipients to directly compare donor $\mathrm{T}$ cell responses in same recipient mice. We observed that $P d l 1^{-} /$donor T cells had increased expression of CTLA-4 and Lag-3 on both CD4 and CD8 T cells, and increased expression of Tim-3 on CD8 T cells (Figure 5, A-C). Higher expression of multiple inhibitory receptors by $\mathrm{Pdll}^{-/}$- donor T cells was associated with reduced IFN- $\gamma$ and granzyme B production (Figure 5, D-F). Comparable results were also obtained in recipient mice coinfused with 
A

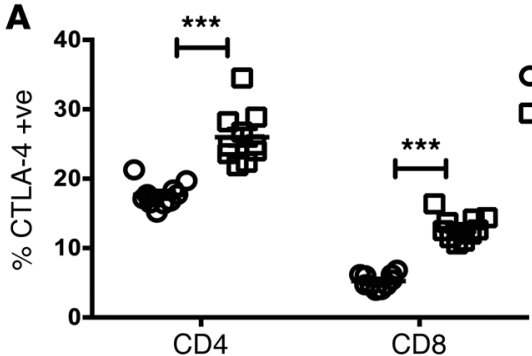

C

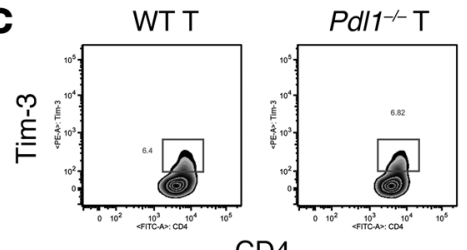

CD4
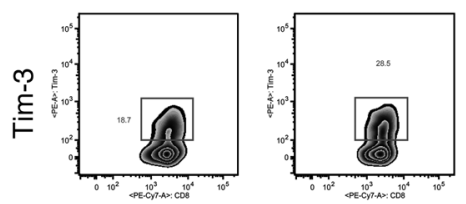

CD8

E

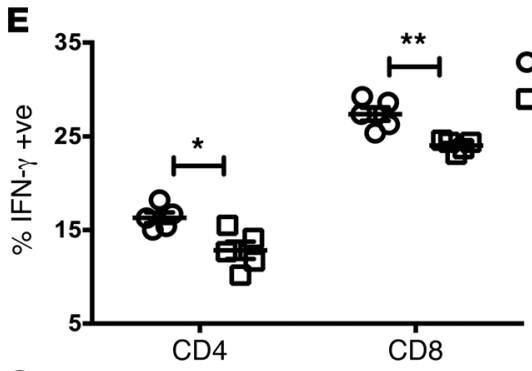

B
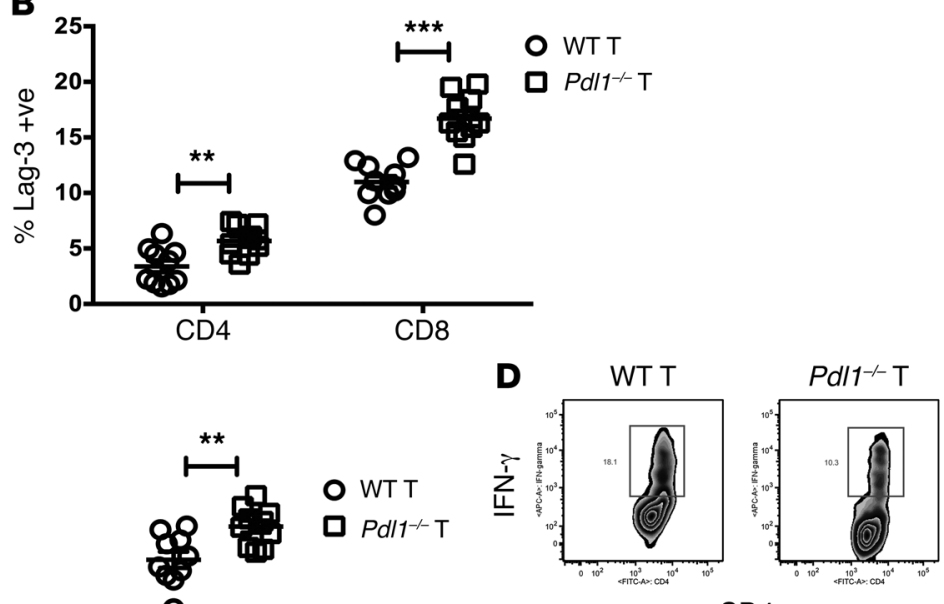

O WT T

口 Pdl1- $T$
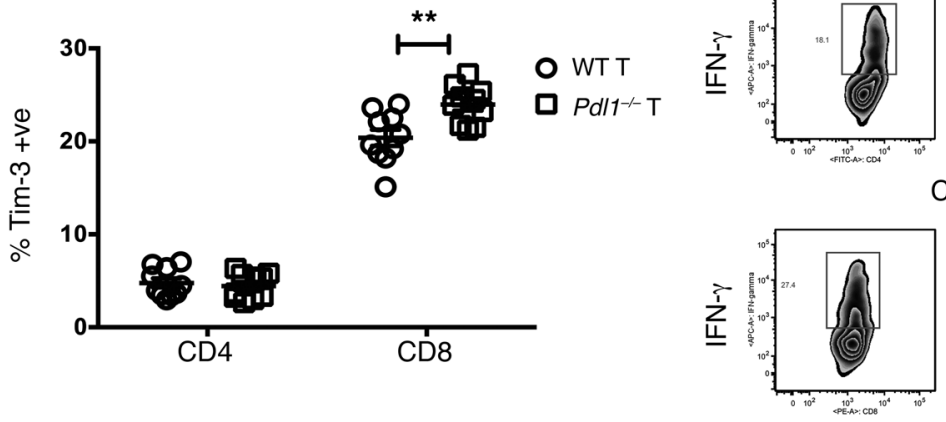

D4

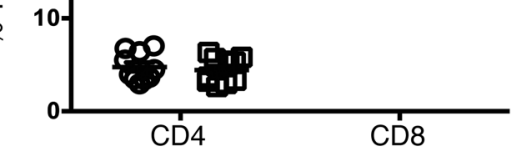

$\mathbf{F}$

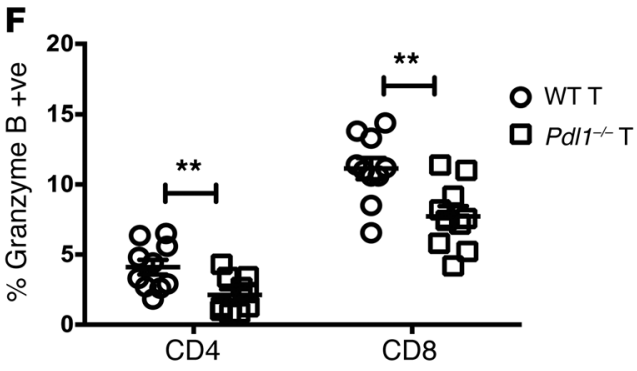

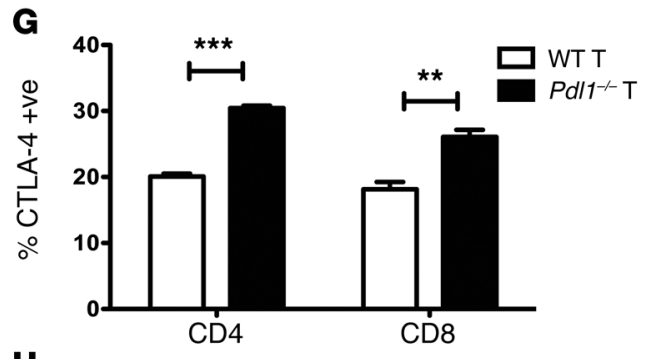
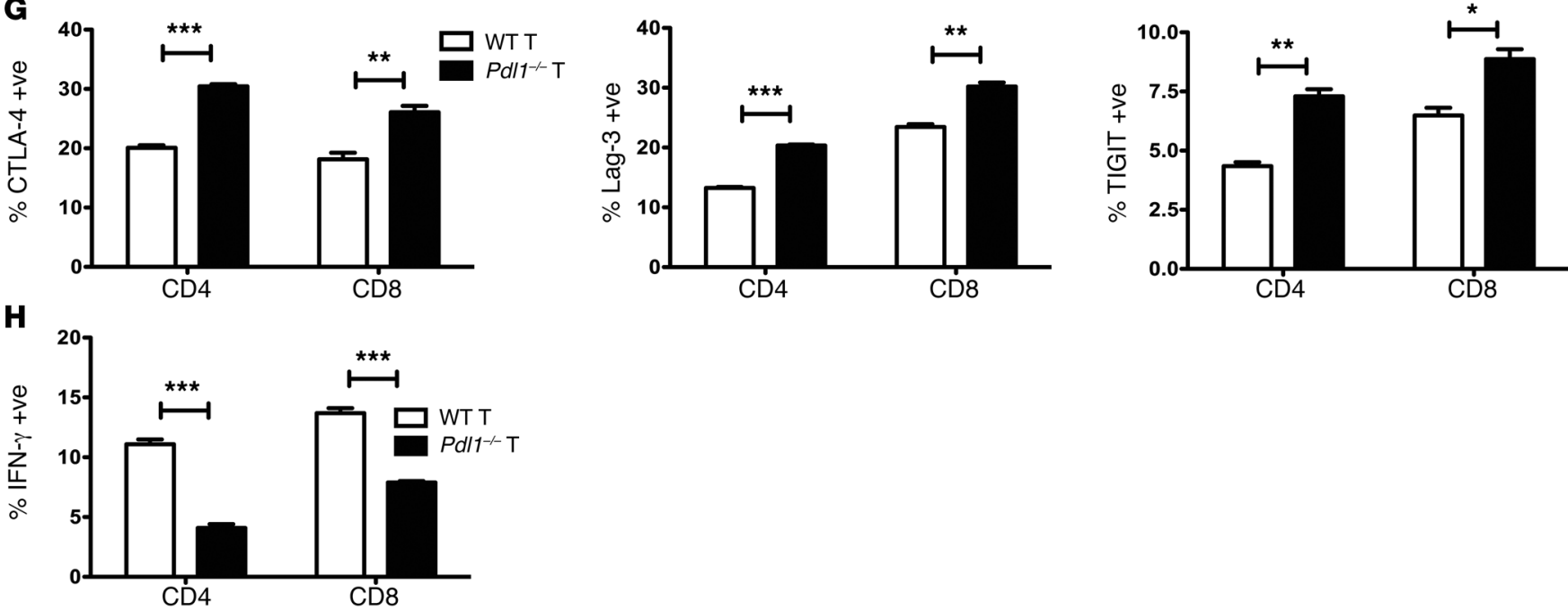

Figure 5. Higher expression of multiple inhibitory receptors by PdI1/-- donor T cells leads to reduced Teff function. (A-F) Lethally irradiated BALB/C recipients were coinfused with $7.5 \times 10^{6} \mathrm{~B} 6$ Ly5.2+ purified T cells plus $7.5 \times 10^{6} \mathrm{Pd} / 1^{-1-}$ purified T cells along with $10^{7}$ WT B6 BM cells. Mice were sacrificed on day 3 after BMT ( $n=5-10$ per group), and donor T cells in spleen were analyzed by flow cytometry for the expression of Lag-3 (B) or Tim-3 (C) or intracellular expression of CTLA-4 (A), IFN- $\gamma(\mathbf{D}$ and E), or granzyme B (F). (G and $\mathbf{H})$ Purified T cells from B6 Ly5.2 mice and Pd/1 ${ }^{-1-}$ mice were cocultured in the presence of suboptimal concentration of plate-bound anti-mCD3 (coating density $5 \mu \mathrm{g} / \mathrm{ml}$ ) and soluble anti-mCD28 $(1 \mu \mathrm{g} / \mathrm{ml})$. Cells were harvested on day 4 and analyzed by flow cytometry for the expression of Lag-3, TIGIT, or intracellular expression of CTLA- 4 or IFN- $\gamma$. (A-H) Data are representative of 2 independent experiments. Data represent mean $\pm \mathrm{SEM}$, and $P$ values were calculated by 2 -tailed $t$ test $(\mathbf{A}-\mathbf{C}$ and $\mathbf{E}-\mathbf{H}) .{ }^{*} P<0.05,{ }^{* *} P<0.01,{ }^{* * *} P<0.001$. 
A

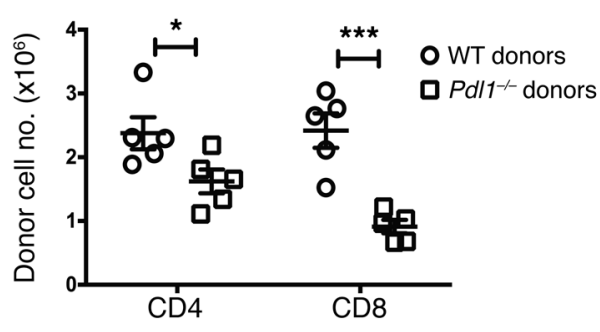

C

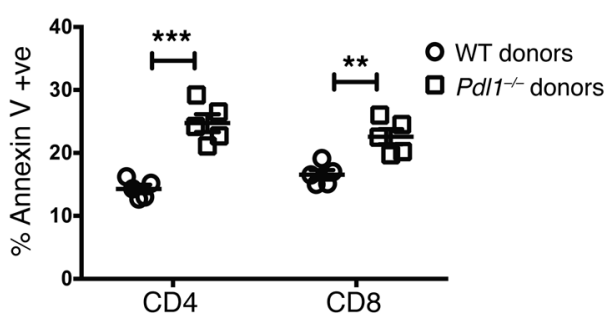

E

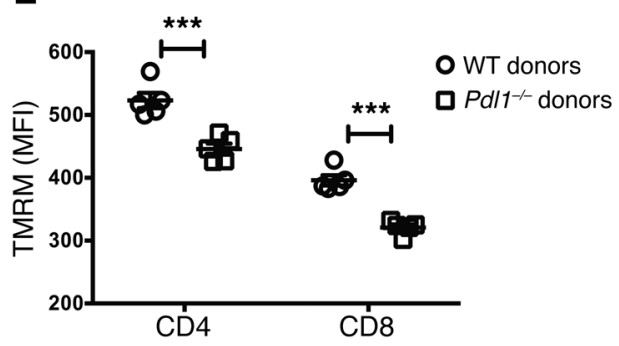

G
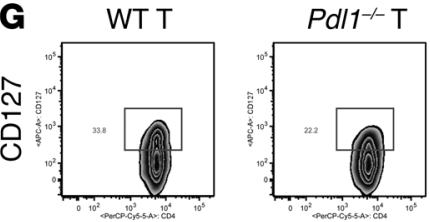

CD4
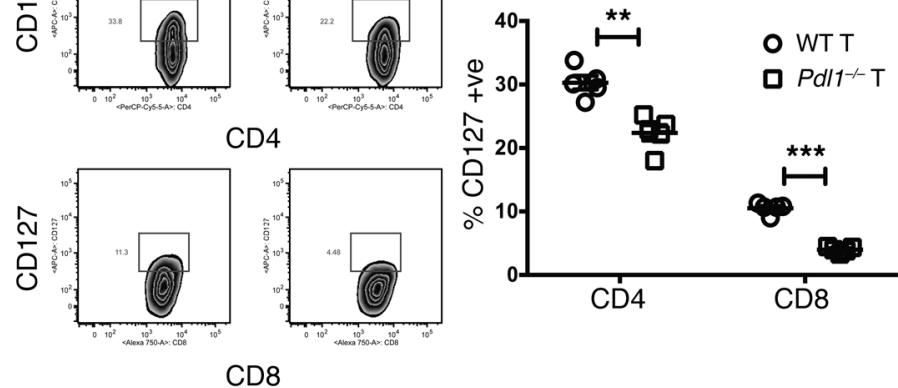

CD8

B

D

$\mathbf{F}$
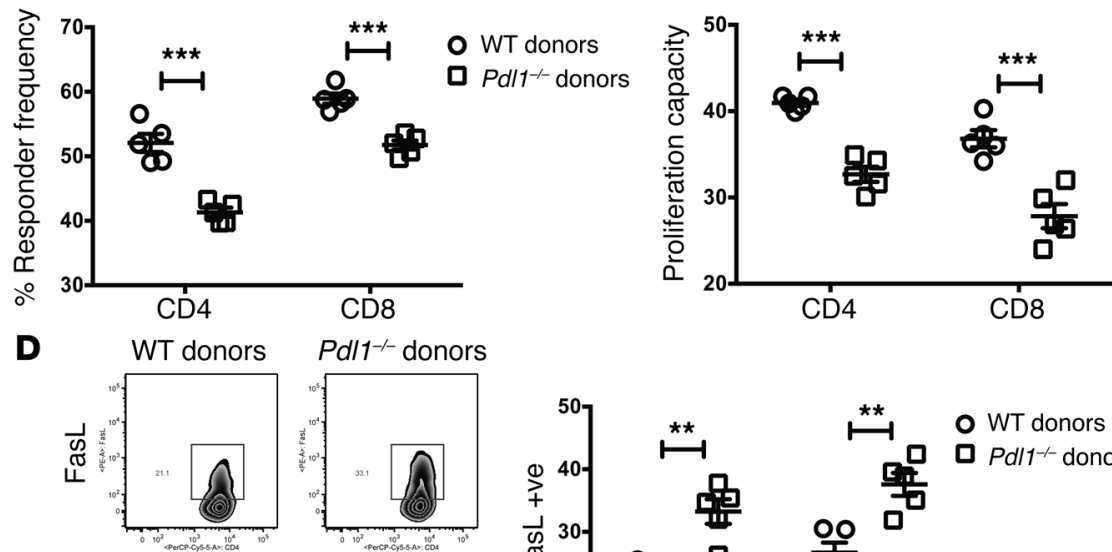

CD4
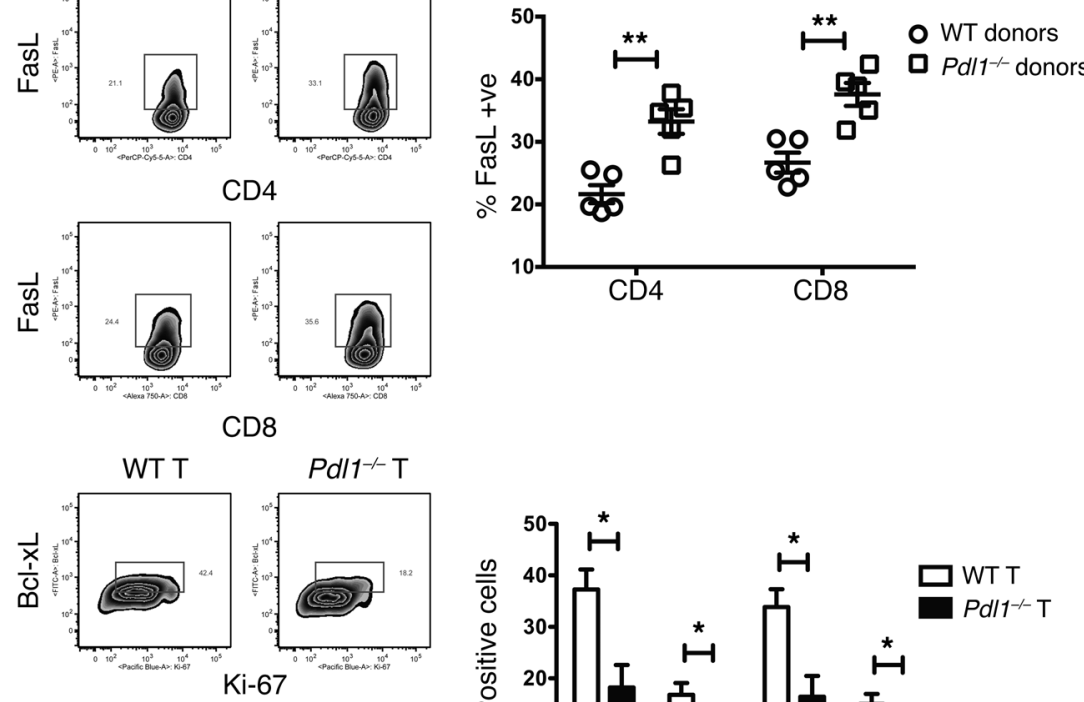

CD4
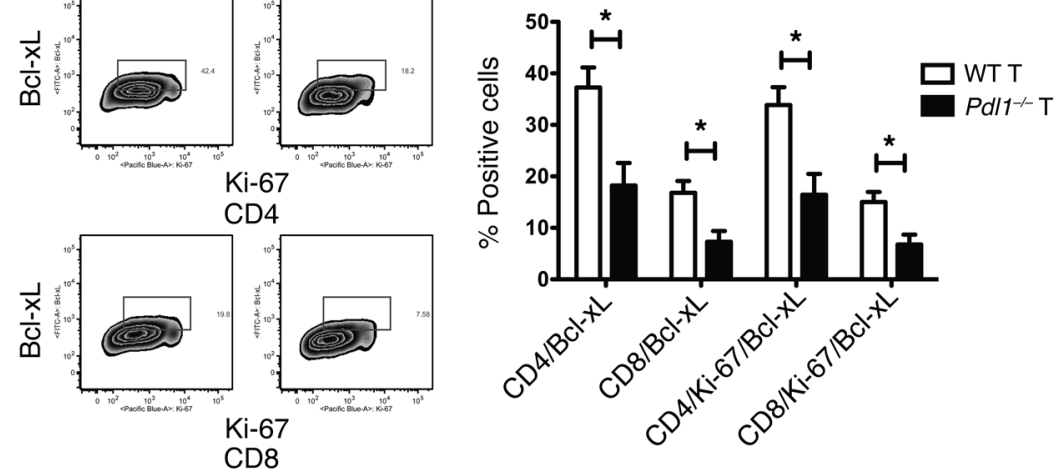

Figure 6. PD-L1 expression on donor T cells is important for their expansion and survival. (A-E) Lethally irradiated $B A L B / c$ recipients were infused with $10^{7}$ WT B6 BM cells plus $20 \times 10^{6}$ CFSE-labeled WT B6 or PdI1 ${ }^{-/-}$splenocytes. Mice were sacrificed on day 4 after BMT, and splenocytes were analyzed by flow cytometry. Donor T cells were analyzed for total cell numbers (A), CFSE dilution (B), annexin V (C), FasL (D), or TMRM expression (E). (F and $\mathbf{G}$ ) Lethally irradiated $B A L B / C$ recipients were infused with $10^{7}$ WT B6 BM cells plus $2 \times 10^{6}$ WT B6 or Pd/1 ${ }^{-/-}$ purified T cells. (F) Intracellular staining was performed on day 5 and analyzed by flow cytometry to detect the percentage of splenic donor $\mathrm{T}$ cells expressing $\mathrm{Bcl}-\mathrm{xL}$ and $\mathrm{Ki}-67$. (G) Splenocytes were also analyzed on day 5 to detect the percentage of donor T cells expressing CD127. (A-G) Data are representative of at least 5 mice per group from 2-3 independent experiments. Data represent mean \pm SEM, and $P$ values were calculated by 2 -tailed $t$ test $(\mathbf{A}-\mathbf{G}) .{ }^{*} P<0.05,{ }^{* *} P<0.01,{ }^{* * *} P<0.001$. equal numbers of WT and $P d l 1^{-/-}$spleen cells (data not shown). Consistent with these in vivo studies, we found that following in vitro stimulation with suboptimal anti-CD3 plus anti-CD28, $\mathrm{Pdl1}^{--} \mathrm{T}$ cells had increased expression of multiple inhibitory receptors and reduced IFN- $\gamma$ production (Figure $5, \mathrm{G}$ and $\mathrm{H}$ ).

$P D-L 1$ expression on donor $T$ cells is important for their expansion and survival. We next undertook studies to investigate potential mechanisms for diminished GVHD induced by $\mathrm{Pdl1}^{-/-}$donor T cells; first, $\mathrm{T}$ cell proliferation was evaluated. In a mixed lymphocyte reac- tion using WT B6 or $\mathrm{Pdl1}^{-/-}$purified T cells as responders and BALB/c BM-derived DC stimulators, we observed significantly decreased responder frequency of $P d l 1^{-/-} \mathrm{T}$ cells (Supplemental Figure 5). Similar findings of decreased proliferation were observed in vivo in a model where lethally irradiated BALB/c mice were infused with WT B6 BM cells plus CFSE-labeled WT B6 or Pdl1 ${ }^{-/-}$splenocytes. Here, we observed a reduction in donor $\mathrm{T}$ cells in the spleens of animals that received $\mathrm{Pdl1}^{-/-}$cells (Figure 6A), coupled with a lower responder frequency and proliferation capacity (Figure 6B). 
A

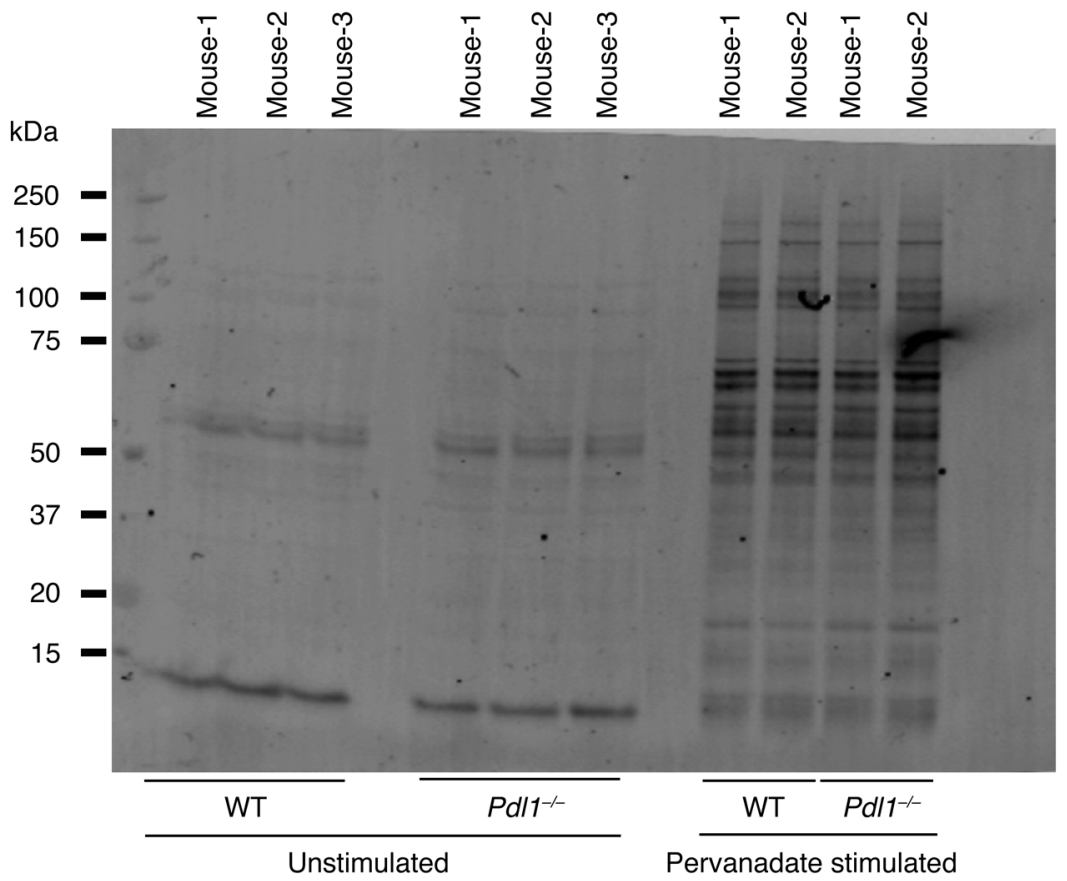

B

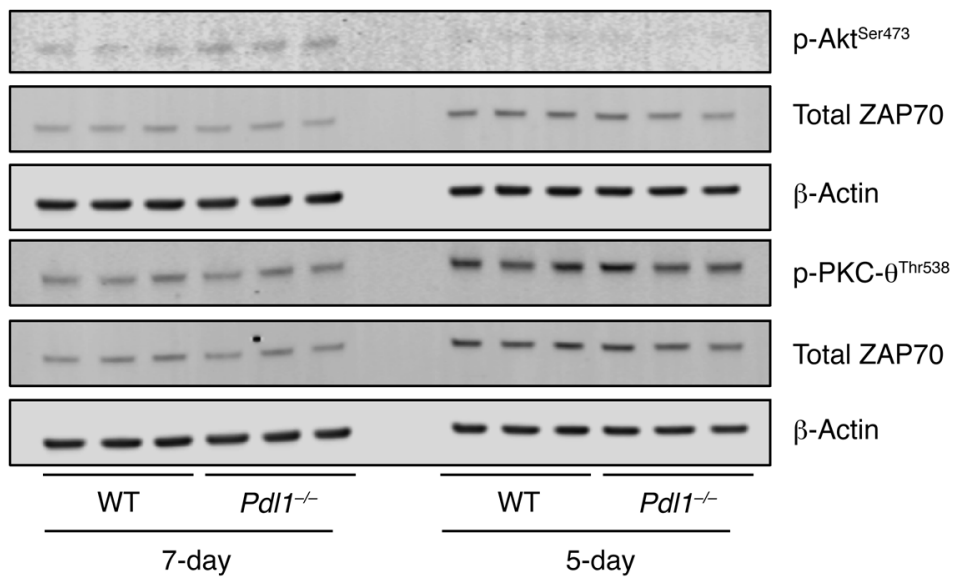

Figure 7. WT and PdI1/-- donor T cells have identical signaling patterns. Lethally irradiated BALB/c recipients were infused with $10^{7}$ WT B6 BM cells plus $2 \times 10^{6}$ WT B6 or Pd/1//- purified T cells. Mice were sacrificed ( $n=10$ per group) on day 5 or day 7 after BMT, and donor T cells were purified from spleen (3-4 spleens were pooled to make 1 pooled sample and 3 pooled samples per group). (A) Cell lysates were prepared from unstimulated or pervanadate-stimulated donor $\mathrm{T}$ cells, and phosphotyrosine Western blot analysis was performed. (B) Cell lysates were prepared from unstimulated T cells and probed for phospho-Akt, ZAP70, $\beta$-actin, and phospho-PKC- $\theta$ for Western blot analysis. Data are representative of 2-3 independent experiments.

Total cell recovery is a function of both proliferation and survival. In addition to diminished proliferation of $\mathrm{Pdl1}^{-/-}$donor $\mathrm{T}$ cells, we also noted increased cell death, as assessed by staining with annexin V and FasL (Figure 6, C and D). To determine whether mitochondrial apoptosis contributed to the increased cell death rate in $\mathrm{Pdll}^{-/-}$donor T cells, we measured tetramethylrhodamine (TMRM), which does not accumulate in depolarized mitochondria and decreases during apoptosis (31). $\mathrm{Pdl1}^{-/-}$donor $\mathrm{T}$ cells underwent more apoptosis as demonstrated by diminished intensity of TMRM staining (Figure 6E). Analysis of Bcl-xL, Bim, and Bcl-2, key mediators of the mitochondrial apoptotic pathway, revealed decreased levels of the antiapoptotic protein
Bcl-xL and of expression of CD127 (the IL-7R $\alpha$ chain that transduces cell survival signals) in $\mathrm{Pdll}^{-/}$donor T cells, without differences in Bim and Bcl-2 expression (Figure 6, F and G, and data not shown). Taken together, these data suggest that PD-L1 expression on donor $\mathrm{T}$ cells is required for both optimal cell expansion and cell survival.

WT and $\mathrm{Pdl1}^{-1-}$ donor $\mathrm{T}$ cells have identical signaling pattern. The findings above of decreased proliferation and survival suggested that loss of PD-L1 expression on donor $\mathrm{T}$ cells might result in altered $\mathrm{T}$ cell signaling. Since little is known about PD-L1 as a T cell signaling molecule, we used an unbiased approach to examine total signaling by phosphotyrosine (Figure 7A) and also interrogated a selected number of molecules (Akt, ZAP70, and PKC- $\theta$; Figure 7B) known to be important for $\mathrm{T}$ cell signaling $(32,33)$. We observed no differences between WT and $\mathrm{Pdl1}^{-/}$donor T cells on day 5 or day 7 after BMT, suggesting that loss of PD-L1 expression does not intrinsically change several known key $\mathrm{T}$ cell signaling pathways.

Metabolic alterations in $\mathrm{Pdl1}^{-/-}$donor T cells during GVHD. To gain further insight into PD-L1 function on T cells, transcriptional profiling of donor $\mathrm{T}$ cells was performed on day 5 after BMT from GVHD recipients of WT or $P d l 1^{-/-}$donor T cells. Individual genes were analyzed for differential expression using the significance analysis of microarrays method (34), with the FDR threshold set at 0.20 for a highly sensitive analysis. A heat map of relative gene expression values for CD4 and CD8 T cells is shown (Figure 8, A and B). Somewhat unexpectedly, we did not find significant differences in individual genes associated with apoptosis. The majority of genes that were differentially expressed were increased in WT T cells. A small group of genes included in Kyoto Encyclopedia of Genes and Genomes (KEGG) metabolism gene sets had increased expression in Pdl1 ${ }^{-/}$CD8 T cells. Using the QuSAGE method (35) applied to pathways from KEGG (36), we performed pathway analysis to evaluate whether nonsignificant expression differences in multiple genes comprising 1 or more pathways can provide evidence of significant differences in overall pathway expression. The apoptosis pathway along with a number of metabolism pathways had increased expression, whereas 4 pathways (pyrimidine metabolism, protein export, proteasome, and ribosome) showed decreased expression in $\mathrm{Pdll}^{-/-}$donor T cells (Figure $8 \mathrm{C}$ ).

The finding of alterations in metabolic pathways prompted a more detailed functional metabolic analysis. In GVHD, donor T cells proliferate rapidly in response to host alloantigenic disparities before migration to specific target organs where they exert 
A

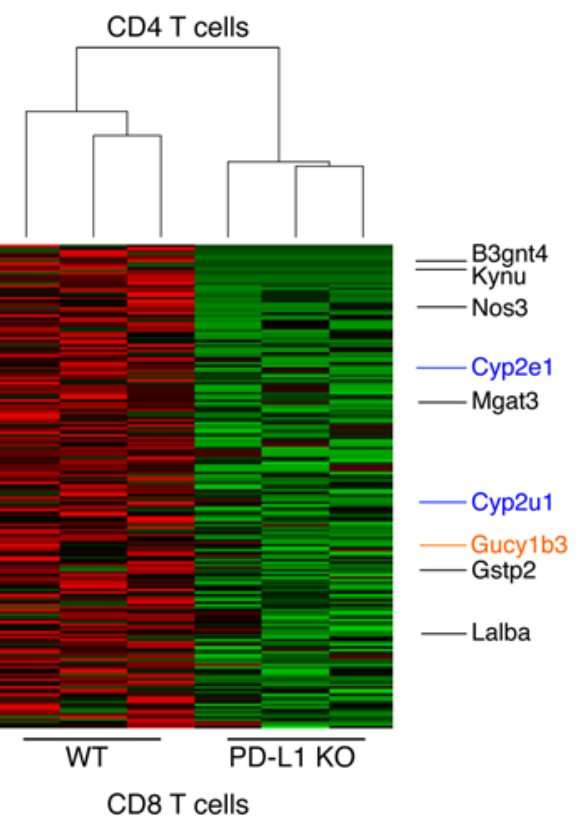

B

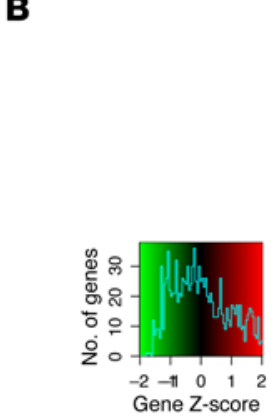

- Purine/pyrimidine

_- Arachidonic acid

- Fatty acid

-Other metabolism

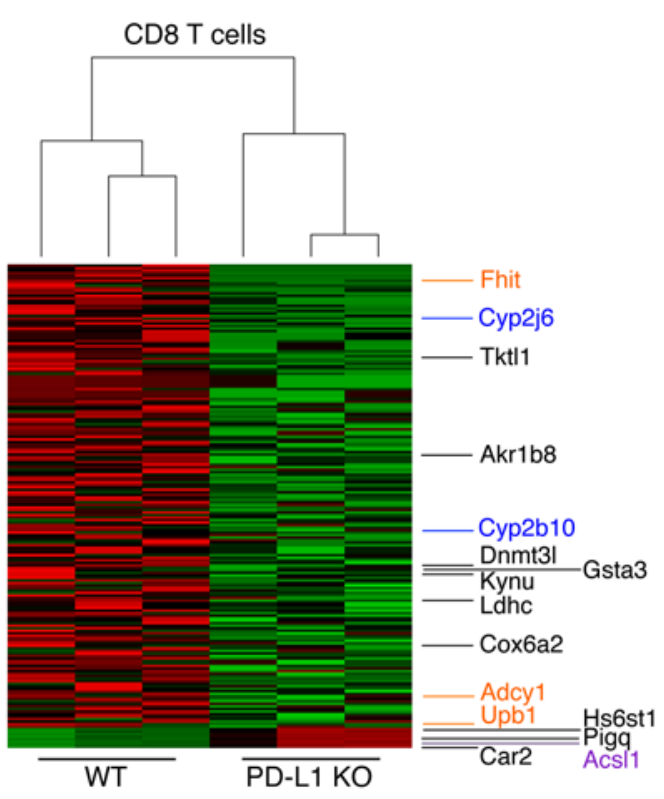

C
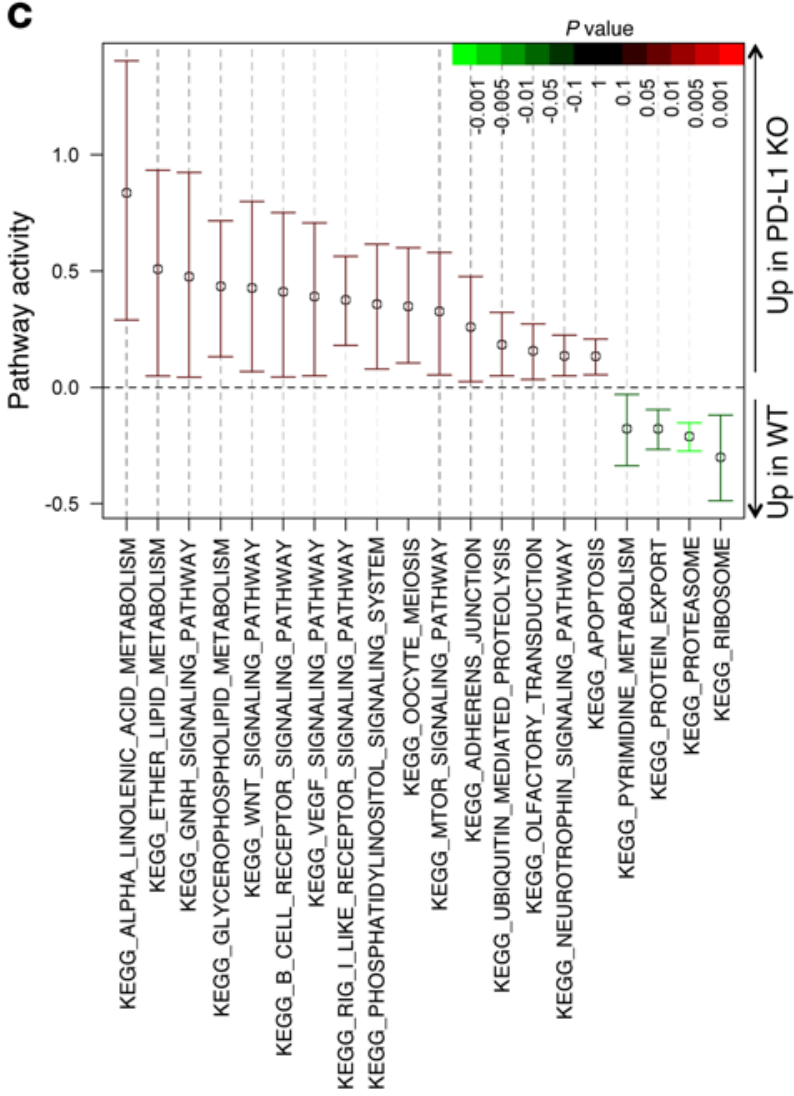

Figure 8. Unsupervised clustering of differentially expressed genes in WT versus PdI1/- donor T cells during GVHD. Lethally irradiated BALB/c recipients were infused with $10^{7}$ WT B6 BM cells plus $2 \times 10^{6} \mathrm{WT}$ B6 or Pdl1 ${ }^{-/}$purified T cells. Mice were sacrificed ( $n=15$ per group) on day 5 after BMT, and donor CD4 and CD8 T cells were purified separately from spleen ( 5 spleens were pooled to make 1 pooled sample and 3 pooled samples per group). Differential expression between WT versus Pd1 $1^{-1-}$ donor CD4 (A) and CD8 (B) T cells was analyzed using SAM. Unsupervised hierarchical clustering on genes that were differentially expressed at an FDR of 0.20 was done and a heat map generated to describe the results. Each column represents an individual pooled sample, and each row represents a single gene. Expression values are scaled by rows with values greater than mean shown in red and values less than mean shown in green, with intensity of color corresponding to relative level of expression. Cenes with membership in a KEGG metabolism gene set are highlighted with text labels. (C) Pathway analysis of WT versus PdI7/-- donor T cells during GVHD. Differential expression of genes comprising various KEGG pathways was tested using QuSAGE, with CD4 and CD8 T cell samples pooled into WT and $P d l 1^{-/}$groups ( $n=6$ pooled samples per group). A list of gene sets included in the analysis is shown in Supplemental Table 2. Gene sets with relative expression differences found at an FDR of 0.20 are shown, along with $95 \%$ confidence intervals for the expression difference. $P$ values for $\mathbf{C}$ were calculated using the QuSAGE method (35).

effector function. To fulfill the bioenergetic and biosynthetic demands of proliferation, migration, and cytolysis, $\mathrm{T}$ cells reprogram their metabolic pathways for a number of substrates, including glucose $(37,38)$, glutamine $(39,40)$, and fatty acids (FAs) $(41$, 42). Therefore, we compared each of these metabolic pathways in WT and $P d l 1^{-/}$donor T cells after allogeneic BMT.

Activated $\mathrm{T}$ cells preferentially generate ATP through aerobic glycolysis (43). Focusing first therefore on glucose metabo- lism, we found that the expression of GLUT1 (the major glucose transporter on hematopoietic cells) (44) was significantly lower in proliferating $\mathrm{Pdl1}^{-/}$donor T cells from BMT recipients (Figure 9A), suggesting decreased glucose uptake and metabolism. Consistent with this, measurements of the extracellular acidification rate (ECAR) in donor $\mathrm{T}$ cells isolated from BMT recipients showed a reduced ECAR in Pdl1 ${ }^{--}$donor T cells following exposure to glucose, as well as a reduction in their maximal glycolytic 
A

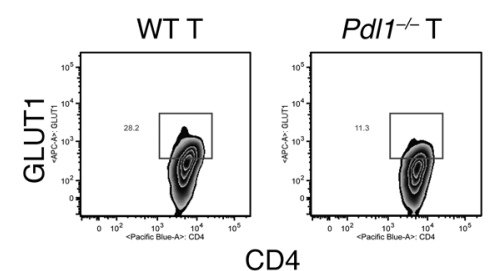

Syngeneic donors $\mathrm{MV}$ Allogeneic Pdl1 ${ }^{-1-}$ donors
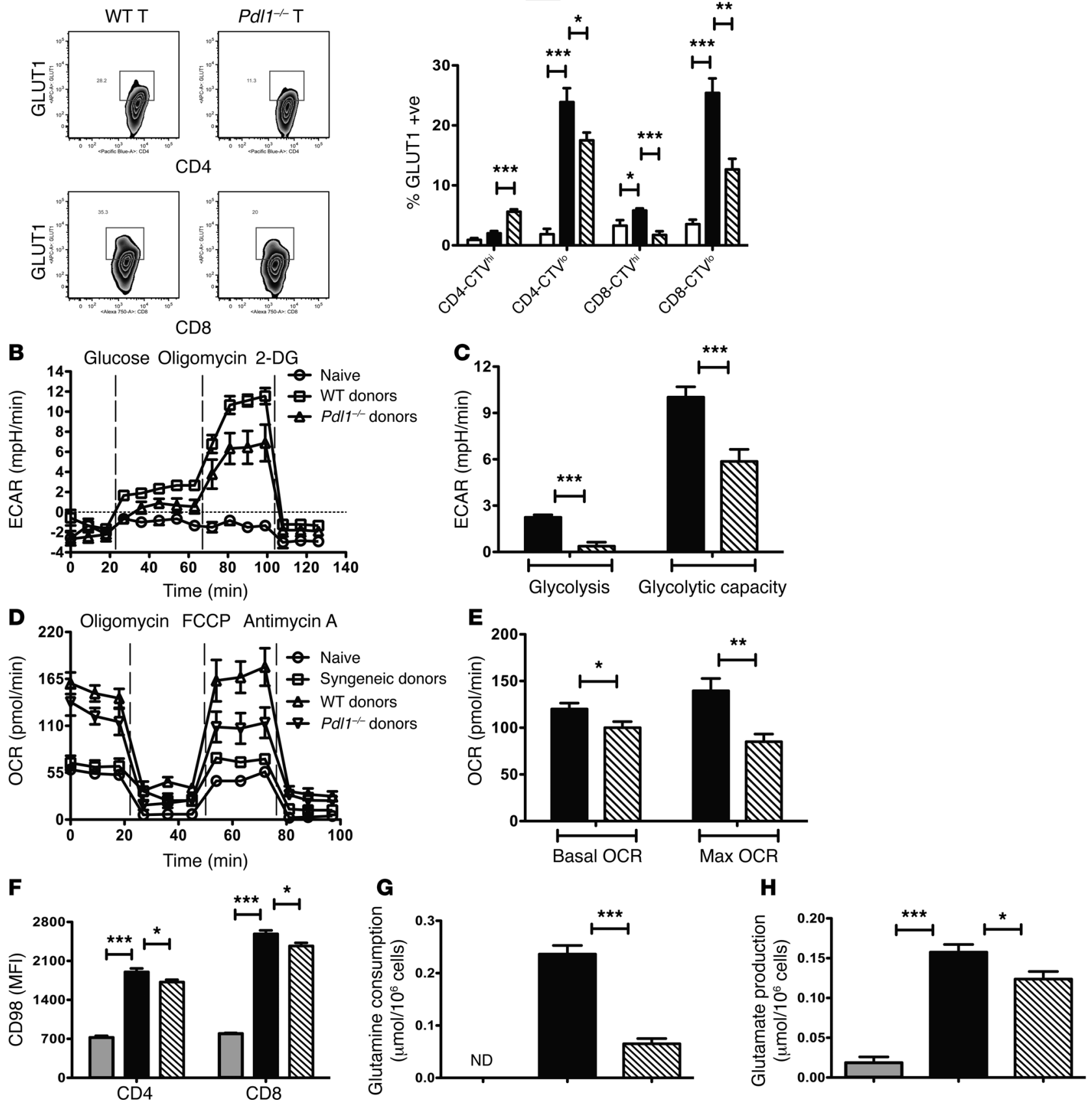

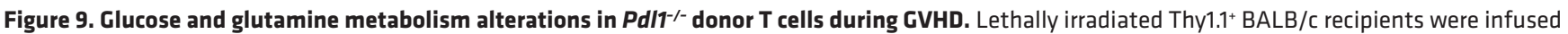
with $10^{7}$ WT B6 BM cells plus $20 \times 10^{6}$ CellTrace Violet-labeled (CTV-labeled) or unlabeled WT B6 or Pdl1 ${ }^{-/-}$splenocytes. Lethally irradiated Thy1.1+ B6 recipients were infused with $10^{7}$ WT B6 BM cells plus $20 \times 10^{6}$ CTV-labeled or unlabeled WT B6 splenocytes and used as syngeneic control. Mice were sacrificed on day 4 after BMT, and experiments were performed as described. (A) Splenocytes were analyzed by flow cytometry for intracellular expression of CLUT1 in undivided (CTVhi) and divided (CTV ${ }^{10}$ ) donor T cells. (B) ECAR of purified donor T cells was measured after addition of glucose, oligomycin, and 2-deoxyglucose (2-DC). (C) Basal glycolysis was measured after addition of glucose, and glycolytic capacity was measured after addition of oligomycin. (D) OCR of purified donor T cells was measured after addition of oligomycin, fluorocarbonyl cyanide phenylhydrazone (FCCP), and antimycin A. (E) Basal OCR (resting OCR - antimycin A OCR) was measured before addition of oligomycin, and maximal OCR was measured after addition of FCCP subtracting nonmitochondrial OCR (antimycin A OCR). (F) Splenic donor T cells were analyzed by flow cytometry for CD98 expression. (G and $\mathbf{H}$ ) Purified donor T cells were cultured at $37^{\circ} \mathrm{C}$ for 4 hours. Culture supernatants were collected, and glutamine consumption and glutamate production were measured using a NovaFlex analyzer. ND, not detected. (B, D, and F-H) T cells purified from naive WT B6 mice $(n=4)$ were included as control. (A and $\mathbf{F})$ Data are representative of 5 mice per group from 2-3 independent experiments. (B-E, $\mathbf{G}$, and $\mathbf{H}$ ) Data are representative of 12 mice per group from 2-3 independent experiments. Data represent mean \pm SEM. $P$ values were calculated by 2 -tailed $t$ test $(\mathbf{A}, \mathbf{C}$, and $\mathbf{E}-\mathbf{H}) .{ }^{*} P<0.05,{ }^{* *} P<0.01,{ }^{* *} P<0.001$. 
A

$\begin{array}{ll}\square \text { Naive } & \square \text { Syngeneic donors } \\ \text { Allogeneic WT donors } & \mathbf{D} \text { Allogeneic } \text { Pdl1 } 1^{-1-} \text { donors }\end{array}$
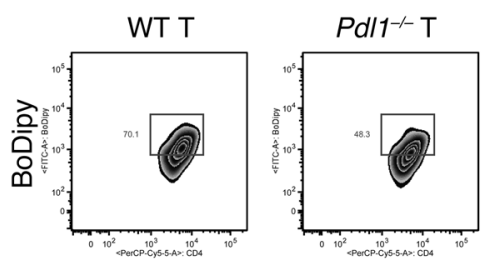

CD4
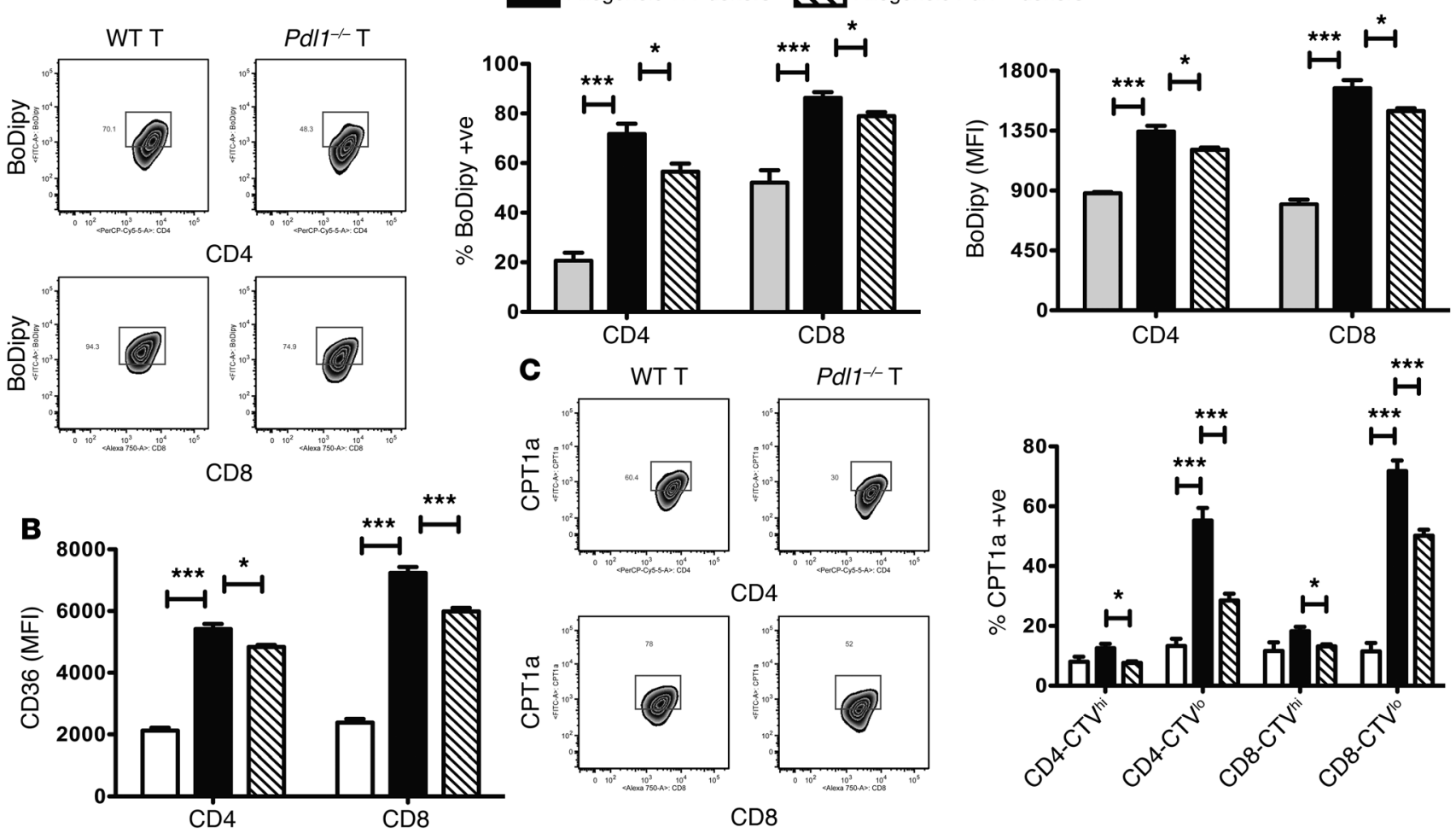

$\mathbf{E}$
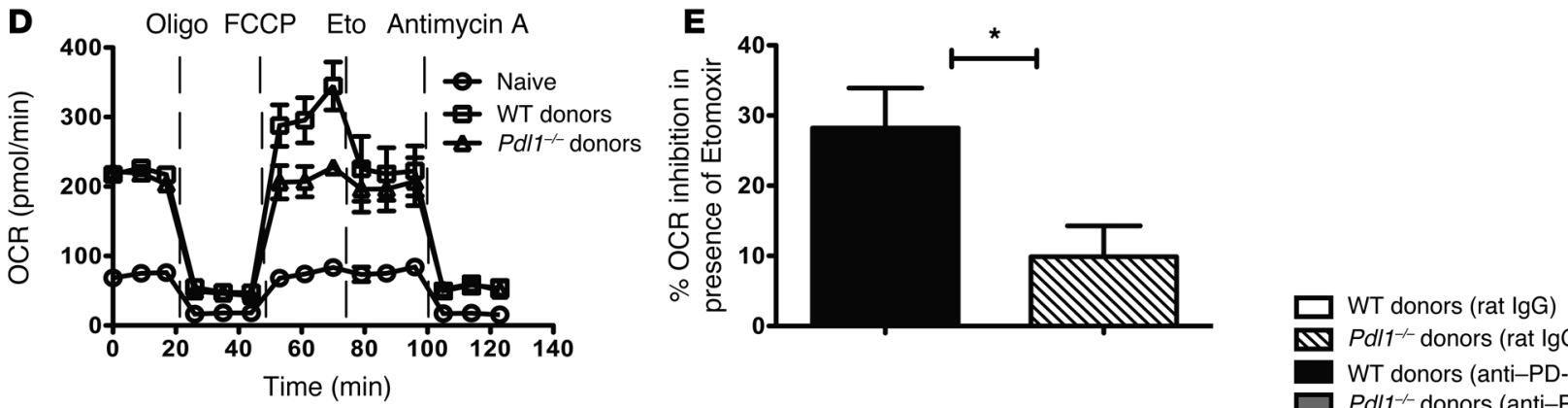

Pd $11^{-1-}$ donors (rat IgG)

WT donors (anti-PD-L1)
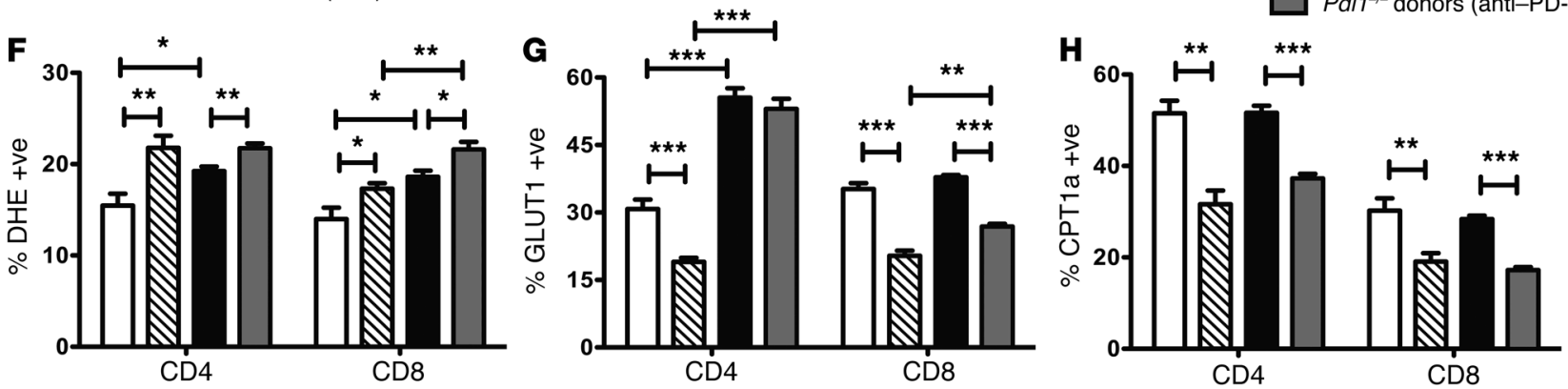

Figure 10. FA metabolism alterations in PdI1/-- donor T cells during GVHD. (A-E) Lethally irradiated Thy1.1+ BALB/c mouse recipients infused with $10^{7}$ WT

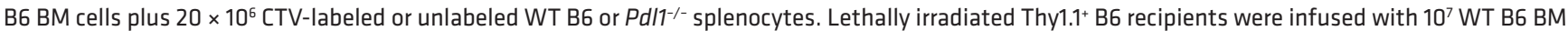
cells plus $20 \times 10^{6} \mathrm{CTV}$-labeled or unlabeled WT B6 splenocytes and used as syngeneic control. Mice were sacrificed on day 4 after BMT, and experiments were performed as described. Splenic donor T cells were analyzed by flow cytometry for BoDipy (A) and CD36 (B) expression. (C) Splenocytes were also analyzed by flow cytometry for intracellular expression of CPT1a in undivided and divided donor T cells. (A-C) Data are representative of 5 mice per group from 2-3 independent experiments. ( $\mathbf{D}$ and $\mathbf{E}$ ) OCR of purified donor T cells was measured after addition of oligomycin, FCCP, etomoxir (Eto), and antimycin A. Data are representative of 12 mice per group. (A and $\mathbf{D})$ T cells from naive WT B6 mice $(n=4)$ were included as control. $(\mathbf{F}-\mathbf{H})$ Reduced apoptosis and enhanced metabolic activities in WT versus Pdl1 ${ }^{-/}$donor T cells are intrinsic properties of donor T cells. Lethally irradiated BALB/c recipients were coinfused with $15 \times 10^{6} \mathrm{~B} 6$ Ly5.2+ splenocytes plus $15 \times 10^{6} \mathrm{Pdl1}^{-/-}$splenocytes along with $10^{7}$ WT B6 BM cells. Recipient mice were treated with isotype-matched control Ab or anti-PD-L1 blocking mAb. Donor T cells in spleen were analyzed on day 4 after BMT ( $n=5$ mice per group) for DHE (F), or intracellular expression of GLUT1 (G) or CPT1a (H) by flow cytometry. Data are representative of 2 independent experiments. Data represent mean \pm SEM. $P$ values were calculated by 2 -tailed $t$ test $(\mathbf{A}-\mathbf{C}$ and $\mathbf{E}-\mathbf{H}) .{ }^{*} P<0.05,{ }^{* *} P<0.01,{ }^{* * *} P<0.001$. 

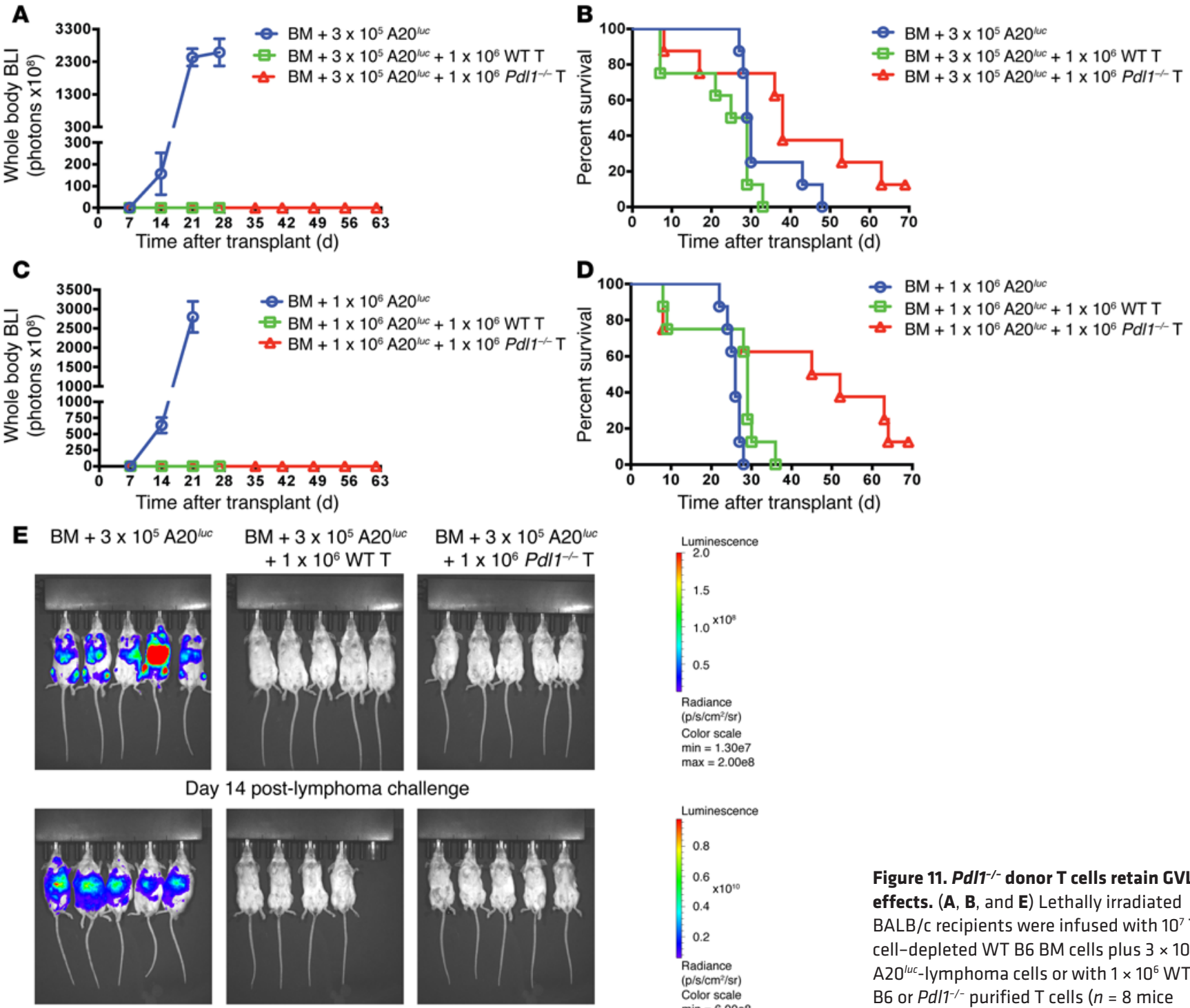

Day 27 post-lymphoma challenge
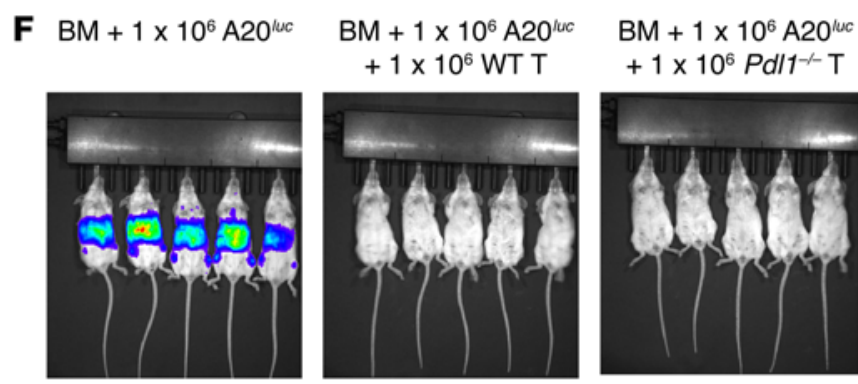

Day 14 post-lymphoma challenge
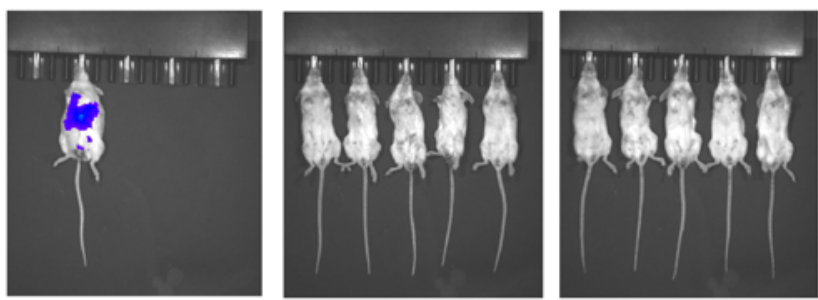

Day 27 post-lymphoma challenge

Figure 11. PdI1/- donor $\mathrm{T}$ cells retain $\mathrm{CVL}$ effects. (A, B, and E) Lethally irradiated $B A L B / c$ recipients were infused with $10^{7} T$ cell-depleted WT B6 BM cells plus $3 \times 10^{5}$

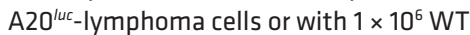
B6 or PdI1 ${ }^{-/-}$purified T cells $(n=8$ mice per group) on day $\mathbf{O}$. (C, $\mathbf{D}$, and $\mathbf{F}$ ) Lethally irradiated $B A L B / C$ recipients were infused with $10^{7} \mathrm{~T}$ cell-depleted WT B6 BM cells plus $1 \times 10^{6} \mathrm{~A} 2 \mathrm{O}^{\text {luc }}$-lymphoma cells or with $1 \times 10^{6}$ WT B6 or Pdl1 $1^{-1-}$ purified T cells ( $n=8$ mice per group) on day 0 . ( $\mathbf{A}$ and $\mathbf{C}$ ) Tumor growth was monitored by luciferase imaging on day 7 , day 14 , day 21 , day 27 , day 35 , day 41 , day 48 , day 55 , and day 62 after BMT. BLI, bioluminescence imaging. (B) Kaplan-Meier survival plot of transplanted mice is shown (recipients of WT vs. $P d l 7^{-/-}$donor T cells, $P=$ 0.0092). (D) Kaplan-Meier survival plot of transplanted mice is shown (recipients of WT vs. $P d l 1^{-1-}$ donor T cells, $P=0.046$ ). (E and $\mathbf{F}$ ) In vivo bioluminescence imaging of A20 luc-lymphoma cells on day 14 and day 27 after BMT. The scale to the right of the images describes the color map for the photon count. $P$ values were calculated by log-rank test (B and D). (A-F) Data were obtained from 1 experiment. 
capacity (after the subsequent addition of oligomycin to suppress mitochondrial ATP production) (Figure 9, B and C).

An alternative mechanism of energy generation is oxidative metabolism, which can use glucose, glutamine, or FAs as substrates. As expected, the $\mathrm{O}_{2}$ consumption rate (OCR), an indicator of oxidative phosphorylation (OXPHOS), was significantly elevated in allogeneic versus syngeneic donor T cells (Figure 9D). Similar to the findings seen with glycolysis, both basal OCR and maximal respiratory capacity (after fluorocarbonyl cyanide phenylhydrazone treatment) were significantly reduced in $\mathrm{Pdll}^{1^{--}}$versus WT donor T cells (Figure 9E).

Glutamine, a key amino acid for $\mathrm{T}$ cell activation, serves as an amine group donor for nucleotide synthesis. Glutamate (the first product of glutamine metabolism) can be converted into $\alpha$-ketoglutarate, which can be metabolized through the TCA cycle to generate citrate, providing a 2-step pathway for glutamine to enter energy metabolism. Consistent with lessened GVHD, we found that cell surface expression of CD98 (glutamine transporter; Figure 9F) and glutamine consumption (Figure 9G) and glutamate production (Figure 9H) were significantly reduced in $\mathrm{Pdl1}^{-/-}$versus WT donor T cells.

We also examined FA oxidation (FAO) as an additional means of energy utilization. We hypothesized that FAO would be lower in $\mathrm{Pdl1}^{-/-}$donor T cells because PD-1 ligation of activated $\mathrm{T}$ cells can limit glycolysis and amino acid metabolism while increasing FAO (45), and GVHD Teffs are under high metabolic stress and known to utilize FAO to provide energy for their survival and/or function. We first measured FA uptake using BoDipy $_{\mathrm{C} 1-\mathrm{C} 12}$, a fluorescent FA analog, and found that it was significantly reduced in $\mathrm{Pdl1^{-/ }}$ donor $\mathrm{T}$ cells (Figure 10A). Consistent with reduced FA uptake, surface expression of CD36, a receptor that binds long-chain FA (46), was significantly reduced in $\mathrm{Pdl1}^{-/-}$donor T cells (Figure 10B). We next analyzed FAO by donor T cells. CPT1a, a metabolic enzyme that controls the rate-limiting step in mitochondrial FAO, was also significantly reduced in proliferating $\mathrm{Pdl1}^{-/-}$versus WT donor T cells (Figure 10C). The use of etomoxir, a specific inhibitor of CPT1a, significantly inhibited maximal respiratory capacity of WT versus $\mathrm{Pdl1}^{-/-}$donor T cells (Figure 10, D and E), confirming that mitochondrial FAO was higher in WT than in $\mathrm{Pdll}^{-/-}$donor T cells.

To address whether increased metabolic activity of WT compared with $\mathrm{Pdl1}^{--}$donor T cells was due to increased GVHD or intrinsic features of donor $\mathrm{T}$ cells, we performed experiments to directly compare the metabolic activity of WT versus $P d l 1^{-/}$donor T cells within an individual recipient that has or does not have active GVHD. Lethally irradiated BALB/c recipients were coinfused with B6 Ly5.2 $2^{+}$splenocytes plus Pdl1 ${ }^{-/}$splenocytes along with WT B6 BM to induce GVHD. To determine whether the absence of PD-L1 engagement with its receptors contributed to any observed metabolic changes, cohorts of recipients were treated with isotype-matched control Ab or anti-PD-L1 mAb (10F.9G2) that blocks all known PD-L1 interactions. Splenocytes were analyzed on day 4 after BMT. WT versus $P d l^{-/-}$donor T cells contained significantly less superoxide (measured by dihydroethidium expression) in recipients treated with rat IgG or anti-PD-L1 (Figure 10F). GLUT1 expression was increased in WT donor T cells in recipients treated with rat IgG, and GLUT1 expression was significantly upregulated on both WT and $\mathrm{Pdl1}^{-/-}$donor T cells in recipients treated with anti-
PD-L1 versus rat IgG (Figure 10G). CPT1a expression was also significantly higher in $\mathrm{WT}$ versus $\mathrm{Pdll}^{-/-}$donor $\mathrm{T}$ cells in recipients treated with rat IgG or anti-PD-L1 (Figure 10H). These data suggest that reduced apoptosis and increased metabolic activities of WT versus $P d l 1^{-/-}$donor T cells may be due to intrinsic differences in these donor $\mathrm{T}$ cells.

Pdl1 ${ }^{-1-}$ donor $T$ cells retain graft-versus-leukemia effects. Because Pdl1 ${ }^{-/}$donor T cells could ameliorate acute GVHD, we sought to determine whether they could retain graft-versus-leukemia (GVL) without inducing lethal GVHD.

Lethally irradiated BALB/c recipients were infused with WT B6 T cell-depleted BM plus A20 $0^{\text {luc }}$-lymphoma cells $\left(3 \times 10^{5}\right.$ or $\left.1 \times 10^{6}\right)$ on day 0 . WT B6 or Pdl1 ${ }^{-/-}$T cells also were administered to groups of mice on day 0 . Mice that received T cell-depleted $\mathrm{BM}$ and $\mathrm{A} 2 \mathrm{O}^{\text {luc }}$ $\left(3 \times 10^{5}\right)$ alone died by day 48 after BMT because of tumor burden (Figure 11, A and B). Mice that received A20 ${ }^{l u c}\left(3 \times 10^{5}\right)$ along with WT or $\mathrm{Pdl1}^{-/-}$donor T cells had no tumor growth (Figure 11, A and E) and died because of GVHD (Figure 11B). GVHD was ameliorated in recipients of $\mathrm{Pdl1}^{-/-}$versus WT donor T cells (Figure 11B), resulting in a significant increase in overall survival rates.

To address whether increased tumor burden would alter GVL effects, cohorts of recipients were infused with 3 times the lethal dose of A20 ${ }^{\text {luc }}$-lymphoma cells. Mice that received A20 $\mathrm{O}^{\text {luc }}\left(1 \times 10^{6}\right)$ along with WT or Pdl1 ${ }^{-/}$donor T cells had no tumor growth (Figure 11, C and F) and died because of GVHD (Figure 11D), again resulting in a significant increase in survival rates in recipients of $\mathrm{Pdl1}^{-/-}$donor $\mathrm{T}$ cells, whereas mice that received $\mathrm{T}$ cell-depleted $\mathrm{BM}$ and $\mathrm{A}^{2} \mathrm{O}^{\text {luc }}\left(1 \times 10^{6}\right)$ alone died by day 28 after BMT because of higher tumor burden (Figure 11, C and D). These data suggest that $\mathrm{Pdl1}^{-/-}$donor T cells can mediate GVL effects in a similar manner to that of WT donor T cells without increasing GVHD.

\section{Discussion}

The PD-1/PD-L1 pathway is a key immune checkpoint that helps regulate normal self-tolerance, but is now known to play a key role in damping immune responses to persistent antigenic stimuli such as chronic viral infections and many malignancies $(47,48)$. As such, mAbs that block PD-1 or PD-L1 enable "exhausted" $\mathrm{T}$ cells to regain normal functional capacities, secrete proinflammatory cytokines, and support productive immune responses (49-51). Consistent with the role in immune augmentation, studies using genetic models in which PD-1 is absent on T cells and experiments using blocking Abs or fusion proteins demonstrate that blocking PD-1 expression or engagement on donor $\mathrm{T}$ cells markedly enhances GVHD lethality (52). In striking contrast, we report here that the in vivo upregulation of PD-L1 on GVHDcausing CD4 and CD8 T cells is necessary for their survival, proliferation, and optimal Teff function.

Expression of PD-L1 on activated WT donor T cells was associated with decreased apoptosis, and increased expression of antiapoptotic molecules including Bcl-xL, which itself is induced by TCR stimulation and upregulated by CD28 signals (53). Elevated expression of Bcl-xL prevents $\mathrm{T}$ cell death in response to cytokine withdrawal and Fas/FasL signaling (53-55). Our finding of lower Bcl-xL and higher FasL expression on $\mathrm{Pdl1}^{-/-}$donor $\mathrm{T}$ cells during GVHD provides a downstream mechanism to explain the higher apoptosis and lower absolute 
numbers of $\mathrm{Pdl1}^{-/-} \mathrm{T}$ cells in the spleen and intestine of GVHD mice. One feature that likely contributes to reduced levels of $\mathrm{Bcl}-\mathrm{xL}$ is lower CD127 expression in Pdl1 ${ }^{-/-} \mathrm{T}$ cells. IL-7 signaling via $\mathrm{CD} 127$ promotes the upregulation of $\mathrm{Bcl}-\mathrm{xL}$ along with $\mathrm{Bcl}-2$ in CD4 effector/memory T cells (56). Also, CD127 signaling is necessary but not sufficient for formation of memory CD8 $\mathrm{T}$ cells during viral infection $(57,58)$ and for the transition of CD4 Teffs into memory cells (59). Together, these findings of reduced CD127 expression and enhanced apoptosis in both CD4 and CD8 $\mathrm{Pdl1}^{-/-}$GVHD Teffs provide a mechanistic explanation for how loss of the PD-L1 on T cells may compromise the generation of protective antitumor immunity (60).

The intense metabolic demand of $\mathrm{T}$ cells in response to activation leads to a series of metabolic adaptations to facilitate expansion and differentiation. These include induction of aerobic glycolysis (61), OXPHOS (62), glutaminolysis, and increase in synthesis of biomolecules (63). T cell metabolism has also been shown to require lipid synthesis (64) or oxidation (65) and amino acid uptake (66). We (22) and others (67) have shown that GVHD results in high metabolic demands for Teffs, increasing their dependency on aerobic glycolysis. Glucose uptake provides a key metabolic control point through the GLUT family of glucose transporters. GLUT1 can promote Teff, as transgenic GLUT1 overexpression selectively increases Teff frequency and leads to inflammatory disease $(38,42)$, whereas GLUT1 deficiency decreases Teff expansion and the ability to induce inflammation (68). We found a significant increase in GLUT1 expression in proliferating WT donor T cells along with increased glycolysis and OXPHOS. Decreased glucose uptake by proliferating $\mathrm{Pdll}^{-/-}$donor $\mathrm{T}$ cells may result in reduced contribution of glucose as a biosynthetic precursor and compromise proliferation. These data are consistent with a recent report showing that tumor cell expression of PD-L1 serves to facilitate glucose uptake and glycolysis, and that checkpoint inhibition acts to restore glucose availability to $\mathrm{T}$ cells in the tumor microenvironment, enabling proliferation and cytokine production (69).

Although memory $\mathrm{T}$ cells preferentially utilize FA metabolism $(41,70)$, Teffs can also rely on FAO during GVHD (65). Increased FA uptake and FAO, and enhanced susceptibility to pharmacologic inhibition of FAO by etomoxir in WT donor T cells, suggest that PD-L1 provides a cell-intrinsic positive stimulus for FA metabolism in alloreactive $\mathrm{T}$ cells undergoing clonal expansion, which may further support $\mathrm{T}$ cell survival, extending in vitro studies by others using human T cells (45). Additionally, the reduced capacity of $P d l 1^{-/-}$Teffs to optimally create energy from glycolysis and FAO is not compensated by increasing OXPHOS, as evident by lower OCR rates or increasing mitochondrial mass (data not shown). Here we show that donor T cells expressing PD-L1 drive concurrent increase in glucose and FA metabolism in the context of alloantigenic stimuli. In contrast, a recent study showed a decreased reliance on FA metabolism in alloreactive T cells (71). It is likely that differences in the nature and strength of alloantigenic stimuli along with the BMT conditions and other factors (e.g., microbiome) that differ between laboratories may lead to models with varying degrees of severity (and hence rapidity of lethality), which may alter the metabolic requirements and pathways engaged to meet the needs of highly proliferative $\mathrm{T}$ cells in a highly inflammatory environment. These speculations, as well as differences in time points examined, may be responsible for the observed utilization of FAO by T cells in our and a prior study (45), in contrast to the recent publication (71).

Collectively, we postulate that relative deficiencies in glycolysis, OXPHOS, and FAO create a metabolic crisis in $\mathrm{Pdl1}^{-/-}$Teffs during GVHD. The high proliferative rate and metabolic needs of GVHD Teffs is outstripped in Pdl1 ${ }^{--}$Teffs, leading to a heightened stress response as measured by higher superoxide production and reduced TMRM accumulation in depolarized mitochondria. It is particularly intriguing to note that these resultant metabolic consequences drive Teffs toward an exhausted $\mathrm{T}$ cell profile, characterized by lower proliferation, proinflammatory cytokine production, cytolytic granule expression, and higher expression of coinhibitory molecules including CTLA-4, Lag-3, TIM-3, and TIGIT, while maintaining PD-1 expression $(72,73)$.

Nonetheless, because PD-L1 is involved in normal thymic selection (74), it is possible that the properties of $\mathrm{Pdl1}^{--} \mathrm{T}$ cells observed here may relate to developmental issues (e.g., those that impair function or alter TCR repertoire) or to PD-L1 expression on non-T cells. Future studies using models where Pdl1 is knocked out selectively in T cells at later stages of development or in peripheral T cells would be needed to precisely address this alternative explanation. Lastly, the reasons for the observed biologic and metabolic effects remain unknown. Possibilities include the lack of PD-L1 signaling in trans to $\mathrm{PD}-\mathrm{1}^{+}$cells (both donor and residual T cells), potential effects of PD-L1 on T cell adhesogenic properties, and colocalization of membrane signaling domains such as would occur in lipid rafts or intracellular adapter proteins to bolster signaling via other pathways.

Whereas PD-L1 signaling of Teffs can regulate the development, maintenance, and function of induced Tregs (75), the function of PD-L1 expressed on thymic-derived Tregs has not been reported to our knowledge. Given the low survival and metabolism of $P d l 1^{-/-}$Teffs during GVHD, we would have expected functional defects in $\mathrm{Pdl1}^{-{ }^{-}}$Tregs, particularly taking into account the defect in FAO used as a major cellular energy source of Tregs. Instead, we found that $P d l 1^{-/-}$Tregs transferred in vivo had comparable GVHD suppressor cell potency. Furthermore, using Treg-depleted donor grafts, we demonstrate that $P d l 1^{--}$Teffs, in the absence of donor thymic-derived Tregs, are unable to cause the same severity of GVHD lethality as WT Teffs. Finally, ameliorated GVHD by $\mathrm{Pdl1}^{-/-}$donor T cells would favor iTreg generation based on lower inflammatory response such as IL-21; however, the findings were very modest, transient, and much lower than iTregs derived from WT donor BM, suggesting that a fundamental difference is occurring in the absence of T cell PD-L1 as the dominant reason for lower GVHD severity. Importantly, GVL effects against A20 lymphoma were largely maintained, despite markedly decreased GVHD lethality in recipients of $\mathrm{Pdl1}^{-/-}$donor $\mathrm{T}$ cells. As a therapeutic strategy, directed PD-L1 targeting of donor T cells by genome engineering or RNA inhibition may be highly advantageous, as Treg suppressor cell potency would be intact while Teffs would be impaired.

Taken together, our results demonstrate the functional significance of PD-L1 expressed by donor T cells in regulating acute GVHD. Greater understanding of the function of PD-L1 expres- 
sion by activated donor $\mathrm{T}$ cells will provide new insight into the regulation of GVHD and suggest strategies to selectively inhibit PD-L1 on donor T cells that may be clinically useful to prevent GVHD, and may provide insights into a counterregulatory role of PD-L1 expression on activated T cells exposed to anti-PD-L1 mAb treatment for cancer.

\section{Methods}

Experimental animals. Female BALB/c $\left(\mathrm{H}-2^{\mathrm{d}}\right)$ mice were purchased from Charles River Laboratories. Female C57BL/6 (H-2 $2^{\mathrm{b}}$; termed B6), B10.BR $\left(\mathrm{H}-2^{\mathrm{k}}\right)$, Thy1.1 $\left(\mathrm{H}-2^{\mathrm{b}}\right)$ congenic, and Ifngr $1^{-/-}\left(\mathrm{H}-2^{\mathrm{b}}\right)$ mice were purchased from The Jackson Laboratory. Female Ly5.2 (H-2 $\left.{ }^{\mathrm{b}}\right)$ congenic mice $\left(\mathrm{CD} 45.1^{+}\right)$were purchased from National Cancer Institute Laboratory. B6-background $P d l 1^{-/-}$and $\mathrm{Pdll}^{-/-} \mathrm{Pdl2^{-/- }}$ mice have been described previously $(21,76)$. BALB/c Thy1.1 congenic mice were obtained from Virginia L. Godfrey (University of North Carolina, Chapel Hill, North Carolina, USA).

Bone marrow transplantation. BMTs were performed as described previously (22). Briefly, recipient mice received total-body irradiation at a lethal dose (BALB/c 700 cGy; B10.BR 1,000 cGy; B6 1,100 cGy) by $\mathrm{x}$-ray on day -1 . BM cells alone or with purified T cells, CD25depleted purified T cells, T cells plus Tregs, or splenocytes were infused i.v. on day 0. Mice were evaluated for evidence of clinical GVHD as described previously (77). Where indicated, irrelevant rat IgG (Rockland Immunochemicals Inc.) or anti-PD-L1 mAb (clone 10F.9G2) was administered i.p. at a dose of $200 \mu \mathrm{g}$ on day 0 and day 3 after BMT.

Flow cytometry. The following unconjugated and fluorochromeconjugated Abs were purchased from eBioscience: anti-CD4 (clone RM4-5), anti-CD8 (clone 53-6.7), anti-CD16/CD32 (clone 93), antiPD-L1 (clone MIH5), anti-PD-L2 (clone Ty25), anti-CD25 (clone PC61.5), anti-CD62L (clone MEL-14), anti-CD44 (clone IM7), antiLPAM-1 (clone DATK32), anti-CCR9 (clone CW-1.2), anti-CXCR3 (clone CXCR3-173), anti-IFN- $\gamma$ (clone XMG1.2), anti-TNF- $\alpha$ (clone MP6-XT22), anti-IL-6 (clone MP5-20F3), anti-CD45.1 (clone A20), anti-CD45.2 (clone 104), anti-Bcl-2 (clone 10C4), anti-CD127 (clone A7R34), anti-CD98 (clone RL388), anti-CD36 (clone 72-1), antiFoxp3 (clone FJK-16s), anti-Helios (clone 22F6), anti-CTLA-4 (clone UC10-4B9), anti-Lag-3 (clone C9B7W), anti-TIM-3 (clone RMT323), anti-granzyme B (clone NGZB), anti-TIGIT (clone GIGD7), antiCD178 (clone MFL3), anti-CD90.1 (clone HIS51), and anti-CD90.2 (clone 30-H12). 7-AAD (catalog 00-6993-50), annexin V (cata$\log 88-8006-74)$, and fixable viability dye (catalog 65-0865) were also purchased from eBioscience. Fluorochrome-conjugated anti$\mathrm{H}-2 \mathrm{~Kb}$ (clone AF6-88.5), anti-PD-1 (clone J43), anti-IL-17A (clone TC11-18H10), and anti-Ki-67 (clone B56) were purchased from BD Biosciences. Anti-Bcl-xL (clone 54H6)-AF488 and anti-Bim (clone C34C5) Abs were purchased from Cell Signaling Technology. Fluorochrome-conjugated anti-CD304 (clone 3E12), anti-CD25 (clone PC61), anti-CD4 (clone RM4-5), and anti-CD8 (clone 53-6.7) were purchased from BioLegend. Anti-GLUT1 (catalog ab14683), antiCPT1a (clone 8F6AE9)-AF488, and anti-CPT2 (clone 1C2AE6) Abs were purchased from Abcam. Secondary Abs were purchased from Jackson ImmunoResearch. CFSE, CellTrace Violet, dihydroethidium (DHE), tetramethylrhodamine (TMRM; methyl ester), MitoTracker Green, MitoTracker Deep Red, and BoDipy $\left(500 / 510 \mathrm{C}_{1}, \mathrm{C}_{12}\right.$ ) were purchased from Invitrogen-Molecular Probes. Cells were stained with viability dye to discriminate live from dead cells. Cell apoptosis was measured using an annexin $\mathrm{V}$ staining kit. Superoxide production by donor T cells was measured by flow cytometry using DHE (a redox-sensitive dye specific for superoxide) as described previously (78). MitoTracker Green and MitoTracker Deep Red staining (79) was performed according to the manufacturer's instructions. Intracellular cytokine staining was performed as described previously (22). Isotype-matched Abs were used as control. Cells were acquired using a BD LSRFortessa flow cytometer (BD Biosciences), and data were analyzed using FlowJo software. Responder frequency and proliferation capacity of donor CD4 and CD8 T cells were calculated as described previously (80).

$T$ cell activation and PD-L1 staining. Total $\mathrm{T}$ cells were freshly obtained from Human Immunology Core (University of Pennsylvania) or thawed from cryopreserved samples. Cells were stimulated with Dynabeads Human T-Expander CD3/CD28 beads (Thermo Fisher) at a cell-to-bead ratio of 1:3 in culture medium. Beads were removed on day 3. Cells were harvested every 24 hours after stimulation for staining. Cells were stained with viability dye, washed, and stained with anti-CD4 (clone RPA-T4; BD Biosciences), anti-CD8 (clone RPA-T8; BD Biosciences), and either anti-PD-L1 (clone MIH1; eBioscience)

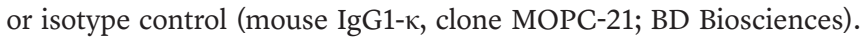
Cells were then washed and acquired using a BD LSR II flow cytometer, and data were analyzed using FlowJo.

$P D-L 1$ expression on $T$ cells during GVHD. Human PBMCs were collected from healthy volunteers (healthy control), and from patients after allogeneic BMT with or without GVHD at the time of collection (Supplemental Table 1). Cryopreserved cells were thawed, washed, and stained with LIVE/DEAD Aqua fixable viability dye (Invitrogen). Cells were washed and stained with the following Abs: anti-CD3 (clone UCHT1; BD Biosciences), anti-CD4 (clone RPA-T4; BD Biosciences), anti-CD8 (clone RPA-T8; BD Biosciences), antiCD14 (clone 61D3; eBioscience), anti-CD20 (clone 2H7; eBioscience), anti-CD28 (clone 28.2; BioLegend), anti-CD45RA (clone HI100; BioLegend), anti-CD45RO (clone UCHL-1; BD Biosciences), anti-CD95 (clone DX2; BD Bioscience), and anti-CD197 (clone 3D12; BD Bioscience). Cells were also stained with either anti-PD-L1 (clone 29E.2A3; BioLegend) or isotype control (mouse IgG2b, clone 27-35; BD Biosciences). Cells were then washed and acquired using a BD LSRFortessa X-18 flow cytometer, and data were analyzed using FlowJo. The percentages of PD-L1 ${ }^{+}$cells were quantified for $\mathrm{CD}^{+}$ $\mathrm{CD}^{-} 4^{-} \mathrm{CD} 2 \mathrm{O}^{-}$and either $\mathrm{CD} 4^{+}$or $\mathrm{CD} 8^{+}$viable lymphocytes using the gating strategy shown in Supplemental Figure 2A.

Treg suppression assay. Tregs were isolated from LNs of WT B6 or $\mathrm{Pdl1}^{-/-}$mice by magnetic-activated cell sorting column selection to more than 93\% purity. Splenocytes isolated from B6 Ly5.2 mice were labeled with CFSE and used as responder cells. Responder cells were stimulated with purified anti-mCD3 mAb $(0.25 \mu \mathrm{g} / \mathrm{ml}$; eBioscience $)$ and were cultured with or without freshly isolated Tregs at the indicated $\mathrm{T}$ cell/Treg ratios. Cells were harvested on day 4 , and proliferation was determined by CFSE dilution.

Histology. Representative mice were sacrificed on day 24 after BMT; harvested organs were processed and stored as described previously (81). Cryosections $(6 \mu \mathrm{m})$ were fixed in acetone and stained with $\mathrm{H} \& \mathrm{E}$, and histopathology scores were assigned as described previously (82).

FITC-dextran permeability assay. FITC-dextran assay was used to evaluate intestinal permeability as described previously (22). Briefly, mice were given 16 mg of FITC-dextran orally; 4 hours later, 
plasma was collected, and fluorescence intensity of each sample was measured on a plate reader.

Colon lymphocyte isolation. Mice were sacrificed on day 24 after BMT, and colons were harvested, cut into pieces, and incubated 3-4 times with $5 \mathrm{mM}$ EDTA in RPMI 1640 with $10 \%$ serum at $37^{\circ} \mathrm{C}$ for 15 minutes. Supernatants containing intraepithelial lymphocytes were discarded. Tissues were then incubated twice with $0.5 \mathrm{mg} / \mathrm{ml}$ and once with $1 \mathrm{mg} / \mathrm{ml}$ of Collagenase D (Roche) in RPMI 1640 with $10 \%$ serum at $37^{\circ} \mathrm{C}$ for 1 hour. Lymphocytes were isolated on a $40 / 80$ Percoll (Sigma-Aldrich) gradient.

$T$ cell activation. Purified T cells (purity $\geq 98 \%$ ) from B6 Ly5.2 mice and $\mathrm{Pdl1}^{-/-}$mice were cocultured in 96-well plates in the presence of plate-bound anti-mCD3 (coating density $5 \mu \mathrm{g} / \mathrm{ml}$ ) and soluble anti-mCD28 $(1 \mu \mathrm{g} / \mathrm{ml})$. Cells were harvested on day 4 and analyzed by flow cytometry.

Mixed lymphocyte reaction. DCs were generated as described previously (83). Briefly, BM cells isolated from BALB/c mice were cultured with recombinant mouse GM-CSF and recombinant mouse IL-4 for 7 days. DCs were then irradiated (1,000 cGy) and used as stimulators. T cells purified from WT B6 or Pdl1/-- mice were labeled with CFSE and used as responder cells. Mixed lymphocyte reaction experiments were performed by coculturing of responder and stimulator cells at different ratios in 96-well plates. Cells were harvested on day 5 and day 6, and $\mathrm{T}$ cell proliferation was determined by CFSE dilution.

Western blot analysis. Mice were sacrificed on day 5 or day 7 after $\mathrm{BMT}$, and donor T cells were purified from spleen. Whole cell lysates were generated from unstimulated or pervanadate-stimulated $\mathrm{T}$ cells (84). Phosphorylated tyrosine (clone P-Tyr-100), phosphorylated Akt (clone D9E), phosphorylated PKC- $\theta$ (clone Thr538), total ZAP70 (clone D1C10E), or $\beta$-actin (clone 8H1OD10) was detected with primary $\mathrm{mAb}$ or polyclonal $\mathrm{Ab}$ (Cell Signaling Technology) followed by anti-mouse $\mathrm{Ab}$ conjugated with IRDye-800CW (LI-COR Biosciences), anti-mouse Ab conjugated with Dylight-680 (Cell Signaling Technology), or anti-rabbit Ab conjugated with Dylight-800 (Cell Signaling Technology). Membranes were visualized with the Odyssey CLx scanner (LI-COR Biosciences).

Metabolism assays. Mice were sacrificed on day 4 after BMT, and donor $\mathrm{T}$ cells were purified from spleen (3 spleens were pooled to make 1 pooled sample and 4 pooled samples per group). ECAR and OCR of purified donor T cells were measured with an XF-24 Extracellular Flux Analyzer (Seahorse Bioscience). Cells were seeded in a plate coated with Cell-Tak (BD Biosciences), and ECAR was measured in $\mathrm{XF}$ media with glutamine alone under basal condition and in response to glucose $(10 \mathrm{mM})$, oligomycin $(1 \mu \mathrm{M})$, and 2-deoxyglucose (50 mM). Also, cells were seeded in a Cell-Tak-coated plate, and OCR was measured in XF media (modified DMEM containing $25 \mathrm{mM}$ glucose, $1 \times$ GlutaMAX (Gibco), and $1 \mathrm{mM}$ sodium pyruvate) under basal condition and in response to oligomycin $(1 \mu \mathrm{M})$, fluorocarbonyl cyanide phenylhydrazone $(0.3 \mu \mathrm{M})$, and antimycin $\mathrm{A}(2 \mu \mathrm{M})$. In selected experiments, OCR was also measured in the presence of etomoxir.

In separate experiments, purified donor $\mathrm{T}$ cells were cultured at $37^{\circ} \mathrm{C}$ for 4 hours, culture supernatants were harvested, and glutamine consumption, glutamate production, and ammonium production were measured using a NovaFlex analyzer (Nova Biomedical). Culture medium without cells was used to normalize the NovaFlex data.

Illumina HiSeq sequencing and determination of individual gene expression levels. Mice were sacrificed on day 5 after BMT, and donor
T cells were purified from spleen ( 5 spleens were pooled to make 1 pooled sample and 3 pooled samples per group). Total RNA was extracted from purified T cells using the Qiagen RNeasy protocol. mRNA-sequence libraries were made according to the Illumina TruSeq protocol and run on 2 lanes of an Illumina HiSeq 2500 sequencer with $1 \times 50$ single-end chemistry (at 6 samples per lane). Sequence data were processed and filtered as described previously by Cancer Genome Atlas (85). Bases and quality control (QC) assessment of sequencing were generated by CASAVA 1.8. QC-passed reads were aligned to the NCBI build 37 (hg19) human reference genome using MapSplice (86). Aligned reads were sorted and indexed using SAMtools, and then translated to transcriptome coordinates and filtered for large inserts and zero mapping quality using UBU 1.0 (https://github.com/mozack/ubu). For the reference transcriptome, UCSC hg19 knownGene was used (87), with genes located on nonstandard chromosomes removed. The abundance of transcripts was then estimated using an expectation-maximization algorithm implemented in the software package RSEM (88) version 1.1.13. Estimated counts were normalized to the upper quartile (87) before comparison of expression across samples.

Differential gene expression analysis. RSEM-normalized expression levels were analyzed for differential expression using the software package SAM implemented in R (samr) $(89,90)$ with FDR calculated according to the method of Benjamini and Hochberg implemented in the samr package (91). Unsupervised hierarchical clustering was done and results plotted using the $\mathrm{R}$ function heatmap. 2 in the gplots package (92), using the centroid clustering and Euclidean distance methods. Genes where differential expression was seen between WT and Pdl1 $^{-/-}$T cells at an FDR level of 0.20 are shown.

Pathway analysis. Pathway analysis was done using the QuSAGE software package implemented in R (35). CD4 and CD8 T cell data were pooled to yield 6 replicates per group (WT vs. $P d l 1^{-1-}$ ). Gene sets tested in KEGG pathways with mouse homologs replacing human genes (those without a mouse homolog excluded from the mouse list) are included in Supplemental Table 2. Pathways with unadjusted $P$ less than 0.05 associated with differential expression between WT and $P d l 1^{-/-}$donor T cell samples are shown.

Lymphoma cell line and GVL studies. A20 is a BALB/c-derived lymphoma cell line that was modified to express luciferase (termed A20 ${ }^{l u c}$ ) as described previously (93). Lethally irradiated BALB/c recipients were infused with $10^{7} \mathrm{~T}$ cell-depleted WT B6 BM cells alone or with 1 $\times 10^{6} \mathrm{WT}$ B 6 or $\mathrm{Pdl1}^{-/}$purified T cells on day 0 . To induce lymphoma, A20 $0^{\text {luc }}$ cells $\left(3 \times 10^{5}\right.$ or $\left.1 \times 10^{6}\right)$ were injected into mice by tail vein injection on day 0 . Tumor growth was monitored weekly by luciferase imaging of lymphoma cells.

Statistics. Data were analyzed using GraphPad Prism (version 5 or 6). Survival data were analyzed using log-rank test. For all other data, 2-tailed Student's $t$ test was used to analyze differences between groups. $P$ less than 0.05 was considered as significant.

Study approval. Mice were bred and housed in a specific pathogen-free facility, and all studies were carried out under protocols approved by IACUC at the University of Minnesota. Peripheral blood samples from healthy donors and patients were obtained following written informed consent in accordance with the Declaration of Helsinki. Samples were randomly selected from a cell bank for the study approved by the IRB at the University of Pennsylvania or Ohio State University, respectively. 
Supplemental material online. Supplemental Table 1 includes patient characteristics. Supplemental Table 2 includes gene sets tested in KEGG pathways with mouse homologs replacing human genes (those without a mouse homolog excluded from the mouse list). There are 5 Supplemental Figures.

\section{Author contributions}

AS designed and performed most of the experiments, analyzed and provided data, designed figures, and wrote the manuscript. RSC, SBL, DBD, CBW, VT, JMP, and SNF performed experiments and provided data. GT, KA, PAT, RF, JSB, LG, and CS performed experiments. BGV and JSS discussed experimental design and provided data. APM assigned pathology scoring. LSK, NWS, and IAB analyzed data. PR and SMD provided patient samples. MCM, MLD, JLR, DAB, WJM, BTF, DHM, JSM, and LAT provided data discussion and edited the manuscript. GJF and AHS provided reagents and edited the manuscript. BRB designed experiments, discussed and analyzed data, and edited the manuscript.

\section{Acknowledgments}

We thank Christopher Lees and colleagues of B.R. Blazar's laboratory for technical assistance, S. Davis (University of Oxford, Oxford, UK) for human PD-L1, and S. Garrett and S. Almo (Einstein School of Medicine, New York, NY) for data on interspecies interactions. This study was supported in part by NIH grants HL056067 (to B.R. Blazar), AI034495 (to B.R. Blazar), AI056299 (to B.R. Blazar), and AI043542 (to M.L. Dustin), and the Wellcome Trust (to M.L. Dustin).

Address correspondence to: Bruce R. Blazar, University of Minnesota, Department of Pediatrics, MMC 109, 420 Delaware Street SE, Minneapolis, Minnesota 55455, USA. Phone: 612.626.1926; E-mail:blaza001@umn.edu.
1. Socie G, Blazar BR. Acute graft-versus-host disease: from the bench to the bedside. Blood. 2009;114(20):4327-4336.

2. Blazar BR, Murphy WJ, Abedi M. Advances in graft-versus-host disease biology and therapy. Nat Rev Immunol. 2012;12(6):443-458.

3. McDonald-Hyman C, Turka LA, Blazar BR. Advances and challenges in immunotherapy for solid organ and hematopoietic stem cell transplantation. Sci Transl Med. 2015;7(280):280rv2.

4. Okazaki T, et al. PD-1 immunoreceptor inhibits B cell receptor-mediated signaling by recruiting src homology 2-domain-containing tyrosine phosphatase 2 to phosphotyrosine. Proc Natl Acad Sci US A. 2001;98(24):13866-13871.

5. Sheppard KA, et al. PD-1 inhibits T-cell receptor induced phosphorylation of the ZAP70/CD3zeta signalosome and downstream signaling to PKCtheta. FEBS Lett. 2004;574(1-3):37-41.

6. Okazaki T, Honjo T. The PD-1-PD-L pathway in immunological tolerance. Trends Immunol. 2006;27(4):195-201

7. Topalian SL, Drake CG, Pardoll DM. Immune checkpoint blockade: a common denominator approach to cancer therapy. Cancer Cell. 2015;27(4):450-461

8. Lesokhin AM, et al. On being less tolerant: enhanced cancer immunosurveillance enabled by targeting checkpoints and agonists of $\mathrm{T}$ cell activation. Sci Transl Med. 2015;7(280):280sr1.

9. Postow MA, Callahan MK, Wolchok JD. Immune checkpoint blockade in cancer therapy. J Clin Oncol. 2015;33(17):1974-1982.

10. Chen L, Han X. Anti-PD-1/PD-L1 therapy of human cancer: past, present, and future. JClin Invest. 2015;125(9):3384-3391.

11. Freeman GJ, et al. Engagement of the PD-1 immunoinhibitory receptor by a novel $\mathrm{B} 7$ family member leads to negative regulation of lymphocyte activation. J Exp Med.2000;192(7):1027-1034.

12. Latchman Y, et al. PD-L2 is a second ligand for PD-1 and inhibits T cell activation. Nat Immunol. 2001;2(3):261-268.

13. Yamazaki T, et al. Expression of programmed death 1 ligands by murine T cells and APC. JImmunol. 2002;169(10):5538-5545.

14. Keir ME, et al. PD-1 and its ligands in tolerance and immunity. Annu Rev Immunol. 2008;26:677-704.

15. Nakae $S$, et al. Mast cells enhance T cell activation: importance of mast cell costimulatory molecules and secreted TNF. JImmunol. 2006;176(4):2238-2248.

16. Butte MJ, et al. Programmed death-1 ligand 1 interacts specifically with the B7-1 costimulatory molecule to inhibit $\mathrm{T}$ cell responses. Immunity. 2007;27(1):111-122.

17. Ansari MJ, et al. The programmed death-1 (PD-1) pathway regulates autoimmune diabetes in nonobese diabetic (NOD) mice. J Exp Med. 2003;198(1):63-69.

18. Gao W, et al. Stimulating PD-1-negative signals concurrent with blocking CD154 co-stimulation induces long-term islet allograft survival. Transplantation. 2003;76(6):994-999.

19. Chen L. Co-inhibitory molecules of the B7-CD28 family in the control of T-cell immunity. Nat Rev Immunol. 2004;4(5):336-347.

20. Sandner SE, et al. Role of the programmed death1 pathway in regulation of alloimmune responses in vivo. J Immunol. 2005;174(6):3408-3415.

21. Keir ME, et al. Tissue expression of PD-L1 mediates peripheral T cell tolerance. J Exp Med. 2006;203(4):883-895.

22. Saha A, et al. Host programmed death ligand 1 is dominant over programmed death ligand 2 expression in regulating graft-versus-host disease lethality. Blood. 2013;122(17):3062-3073.

23. Asakura S, et al. Alloantigen expression on nonhematopoietic cells reduces graft-versusleukemia effects in mice. JClin Invest. 2010;120(7):2370-2378.

24. Flutter B, et al. Nonhematopoietic antigen blocks memory programming of alloreactive $\mathrm{CD} 8^{+} \mathrm{T}$ cells and drives their eventual exhaustion in mouse models of bone marrow transplantation. JClin Invest. 2010;120(11):3855-3868.

25. Petrovic A, et al. LPAM ( $\alpha 4 \beta 7$ integrin) is an important homing integrin on alloreactive $\mathrm{T}$ cells in the development of intestinal graft-versushost disease. Blood. 2004;103(4):1542-1547.

26. Wysocki CA, et al. Leukocyte migration and graft-versus-host disease. Blood. 2005;105(11):4191-4199.

27. Brandl K, et al. Enhanced sensitivity to DSS colitis caused by a hypomorphic Mbtps1 mutation disrupting the ATF6-driven unfolded protein response. Proc Natl Acad Sci U S A. 2009;106(9):3300-3305.

28. Taylor PA, Noelle RJ, Blazar BR. CD4(+)CD25(+) immune regulatory cells are required for induction of tolerance to alloantigen via costimulatory blockade. J Exp Med. 2001;193(11):1311-1318.

29. Taylor PA, Lees CJ, Blazar BR. The infusion of ex vivo activated and expanded $\mathrm{CD} 4(+) \mathrm{CD} 25(+)$ immune regulatory cells inhibits graft-versus-host disease lethality. Blood. 2002;99(10):3493-3499.

30. Bucher C, et al. IL-21 blockade reduces graftversus-host disease mortality by supporting inducible $\mathrm{T}$ regulatory cell generation. Blood. 2009;114(26):5375-5384.

31. Rasola A, Geuna M. A flow cytometry assay simultaneously detects independent apoptotic parameters. Cytometry. 2001;45(2):151-157.

32. Valenzuela JO, et al. PKC $\theta$ is required for alloreactivity and GVHD but not for immune responses toward leukemia and infection in mice. JClin Invest. 2009;119(12):3774-3786.

33. Wang X, et al. Regulation of PKC- $\theta$ function by phosphorylation in $\mathrm{T}$ cell receptor signaling. Front Immunol. 2012;3:197.

34. Li J, Tibshirani R. Finding consistent patterns: a nonparametric approach for identifying differential expression in RNA-Seq data. Stat Methods Med Res. 2013;22(5):519-536.

35. Yaari G, et al. Quantitative set analysis for gene expression: a method to quantify gene set differential expression including gene-gene correlations. Nucleic Acids Res. 2013;41(18):e170.

36. Kanehisa M, et al. KEGG for integration and interpretation of large-scale molecular data sets. Nucleic Acids Res. 2012;40(Database issue):D109-D114.

37. Frauwirth KA, et al. The CD28 signaling pathway regulates glucose metabolism. Immunity. 2002;16(6):769-777.

38. Jacobs SR, et al. Glucose uptake is limiting in $\mathrm{T}$ cell activation and requires $\mathrm{CD} 28$-mediated Akt-dependent and independent pathways. JImmunol. 2008;180(7):4476-4486.

39. Carr EL, et al. Glutamine uptake and metabolism are coordinately regulated by ERK/MAPK 
during T lymphocyte activation. JImmunol. 2010;185(2):1037-1044.

40. Wang R, et al. The transcription factor Myc controls metabolic reprogramming upon T lymphocyte activation. Immunity. 2011;35(6):871-882.

41. Pearce EL, et al. Enhancing CD8 T-cell memory by modulating fatty acid metabolism. Nature. 2009;460(7251):103-107.

42. Michalek RD, et al. Cutting edge: distinct glycolytic and lipid oxidative metabolic programs are essential for effector and regulatory CD $4+\mathrm{T}$ cell subsets. J Immunol. 2011;186(6):3299-3303.

43. Maclver NJ, Michalek RD, Rathmell JC. Metabolic regulation of T lymphocytes. Annu Rev Immunol. 2013;31:259-283.

44. Maclver NJ, et al. Glucose metabolism in lymphocytes is a regulated process with significant effects on immune cell function and survival. J Leukoc Biol. 2008;84(4):949-957.

45. Patsoukis N, et al. PD-1 alters T-cell metabolic reprogramming by inhibiting glycolysis and promoting lipolysis and fatty acid oxidation. Nat Commun. 2015;6:6692.

46. Silverstein RL, Febbraio M. CD36, a scavenger receptor involved in immunity, metabolism, angiogenesis, and behavior. Sci Signal. 2009;2(72):re3.

47. Sakthivel P, Gereke M, Bruder D. Therapeutic intervention in cancer and chronic viral infection: antibody mediated manipulation of PD-1/PD-L1 interaction. Rev Recent Clin Trials. 2012;7(1):10-23.

48. Kulpa DA, et al. PD-1 coinhibitory signals: the link between pathogenesis and protection. Semin Immunol. 2013;25(3):219-227.

49. Barber DL, et al. Restoring function in exhausted CD8 T cells during chronic viral infection. Nature. 2006;439(7077):682-687.

50. Topalian SL, et al. Safety, activity, and immune correlates of anti-PD-1 antibody in cancer. $N$ Engl JMed. 2012;366(26):2443-2454.

51. Brahmer JR, et al. Safety and activity of antiPD-L1 antibody in patients with advanced cancer. N Engl JMed. 2012;366(26):2455-2465.

52. Blazar BR, et al. Blockade of programmed death-1 engagement accelerates graft-versushost disease lethality by an IFN- $\gamma$-dependent mechanism. J Immunol. 2003;171(3):1272-1277.

53. Boise LH, et al. CD28 costimulation can promote T cell survival by enhancing the expression of Bcl-XL. Immunity. 1995;3(1):87-98.

54. Scaffidi C, et al. Two CD95 (APO-1/Fas) signaling pathways. $E M B O J .1998 ; 17(6): 1675-1687$.

55. Farley N, et al. p38 mitogen-activated protein kinase mediates the Fas-induced mitochondrial death pathway in CD8 ${ }^{+} \mathrm{T}$ cells. Mol Cell Biol. 2006;26(6):2118-2129.

56. Chetoui N, et al. Interleukin-7 promotes the survival of human $\mathrm{CD}^{+}$effector/memory T cells by up-regulating $\mathrm{Bcl}-2$ proteins and activating the JAK/STAT signaling pathway. Immunology. 2010;130(3):418-426.

57. Kaech SM, et al. Selective expression of the interleukin 7 receptor identifies effector CD8 T cells that give rise to long-lived memory cells. Nat Immunol. 2003;4(12):1191-1198.

58. Hand TW, Morre M, Kaech SM. Expression of IL-7 receptor alpha is necessary but not suffi- cient for the formation of memory CD8 T cells during viral infection. Proc Natl Acad Sci U S A. 2007;104(28):11730-11735.

59. Li J, Huston G, Swain SL. IL-7 promotes the transition of CD4 effectors to persistent memory cells. J Exp Med. 2003;198(12):1807-1815.

60. Pulko V, et al. B7-H1 expressed by activated CD8 T cells is essential for their survival. J Immunol. 2011;187(11):5606-5614.

61. Caro-Maldonado A, Gerriets VA, Rathmell JC. Matched and mismatched metabolic fuels in lymphocyte function. Semin Immunol. 2012;24(6):405-413.

62. Chang $\mathrm{CH}$, et al. Posttranscriptional control of $\mathrm{T}$ cell effector function by aerobic glycolysis. Cell. 2013;153(6):1239-1251.

63. Wang R, Green DR. Metabolic checkpoints in activated T cells. Nat Immunol. 2012;13(10):907-915.

64. Kidani Y, et al. Sterol regulatory element-binding proteins are essential for the metabolic programming of effector T cells and adaptive immunity. Nat Immunol. 2013;14(5):489-499.

65. Byersdorfer CA, et al. Effector T cells require fatty acid metabolism during murine graft-versus-host disease. Blood. 2013;122(18):3230-3237.

66. Sinclair LV, et al. Control of amino-acid transport by antigen receptors coordinates the metabolic reprogramming essential for $\mathrm{T}$ cell differentiation. Nat Immunol. 2013;14(5):500-508.

67. Gatza E, et al. Manipulating the bioenergetics of alloreactive $\mathrm{T}$ cells causes their selective apoptosis and arrests graft-versus-host disease. $\mathrm{Sci}$ Transl Med. 2011;3(67):67ra8.

68. Macintyre AN, et al. The glucose transporter Glut1 is selectively essential for CD4 T cell activation and effector function. Cell Metab. 2014;20(1):61-72.

69. Chang CH, et al. Metabolic competition in the tumor microenvironment is a driver of cancer progression. Cell. 2015;162(6):1229-1241.

70. O'Sullivan D, et al. Memory CD8(+) T cells use cell-intrinsic lipolysis to support the metabolic programming necessary for development. Immunity. 2014;41(1):75-88.

71. Nguyen HD, et al. Metabolic reprogramming of alloantigen-activated $\mathrm{T}$ cells after hematopoietic cell transplantation. J Clin Invest. 2016;126(4):1337-1352.

72. Wherry EJ. T cell exhaustion. Nat Immunol. 2011;12(6):492-499.

73. Odorizzi PM, et al. Genetic absence of PD-1 promotes accumulation of terminally differentiated exhausted CD8 ${ }^{+}$T cells. J Exp Med. 2015;212(7):1125-1137.

74. Keir ME, Latchman YE, Freeman GJ, Sharpe AH. Programmed death-1 (PD-1):PD-ligand 1 interactions inhibit TCR-mediated positive selection of thymocytes. J Immunol. 2005;175(11):7372-7379.

75. Francisco LM, et al. PD-L1 regulates the development, maintenance, and function of induced regulatory T cells. JExp Med. 2009;206(13):3015-3029.

76. Latchman YE, et al. PD-L1-deficient mice show that PD-L1 on T cells, antigen-presenting cells, and host tissues negatively regulates T cells. Proc Natl Acad Sci U S A. 2004;101(29):10691-10696.

77. Cooke KR, et al. An experimental model of idiopathic pneumonia syndrome after bone marrow transplantation. 1. The roles of minor $\mathrm{H}$ antigens and endotoxin. Blood. 1996;88(8):3230-3239.

78. Blatt NB, et al. Benzodiazepine-induced superoxide signals B cell apoptosis: mechanistic insight and potential therapeutic utility. J Clin Invest. 2002;110(8):1123-1132.

79. Zhou R, et al. A role for mitochondria in NLRP3 inflammasome activation. Nature. 2011;469(7329):221-225.

80. Wells AD, Gudmundsdottir H, Turka LA. Following the fate of individual $\mathrm{T}$ cells throughout activation and clonal expansion: signals from $\mathrm{T}$ cell receptor and CD28 differentially regulate the induction and duration of a proliferative response. JClin Invest. 1997;100(12):3173-3183.

81. Srinivasan M, et al. Donor B-cell alloantibody deposition and germinal center formation are required for the development of murine chronic GVHD and bronchiolitis obliterans. Blood. 2012;119(6):1570-1580.

82. Blazar BR, et al. Engraftment of severe combined immune deficient mice receiving allogeneic bone marrow via in utero or postnatal transfer. Blood. 1998;92(10):3949-3959.

83. Saha A, et al. Therapy of established tumors in a novel murine model transgenic for human carcinoembryonic antigen and HLA-A2 with a combination of anti-idiotype vaccine and CTL peptides of carcinoembryonic antigen. Cancer Res. 2007;67(6):2881-2892.

84. Chemnitz JM, et al. B and T lymphocyte attenuator-mediated signal transduction provides a potent inhibitory signal to primary human CD $4 \mathrm{~T}$ cells that can be initiated by multiple phosphotyrosine motifs. JImmunol. 2006;176(11):6603-6614.

85. Weinstein JN, et al. The Cancer Genome Atlas Pan-Cancer analysis project. Nat Genet. 2013;45(10):1113-1120.

86. Wang K, et al. MapSplice: accurate mapping of RNA-seq reads for splice junction discovery. Nucleic Acids Res. 2010;38(18):e178.

87. Hammerman PS, et al. Comprehensive genomic characterization of squamous cell lung cancers. Nature. 2012;489(7417):519-525.

88. Li B, Dewey CN. RSEM: accurate transcript quantification from RNA-Seq data with or without a reference genome. BMC Bioinformatics. 2011;12:323.

89. Li J, Witten DM, Johnstone IM, Tibshirani R. Normalization, testing, and false discovery rate estimation for RNA-sequencing data. Biostatistics. 2012;13(3):523-538.

90. Li J, Tibshirani R. Finding consistent patterns: a nonparametric approach for identifying differential expression in RNA-Seq data. Stat Methods Med Res. 2013;22(5):519-536.

91. Benjamini Y, Hochberg Y. Controlling the false discovery rate - a practical and powerful approach to multiple testing. JRoy Stat Soc B Met. 1995;57(1):289-300.

92. Warnes GR, et al. gplots: Various R Programming Tools for Plotting Data. R package version 2.17.0. CRAN.R Project Web site. http://CRAN.R-project.org/package=gplots. Updated March 30, 2016. Accessed May 3, 2016.

93. Taylor PA, et al. Insights into the mechanism of FTY720 and compatibility with regulatory T cells for the inhibition of graft-versus-host disease (GVHD). Blood. 2007;110(9):3480-3488. 